\title{
How Spice is Stirred in the Bay of Bengal 0
}

\author{
G. SPIRO JAEGER \\ Massachusetts Institute of Technology, Cambridge, and Woods Hole Oceanographic Institution, Woods Hole, Massachusetts \\ J. A. MACKINNON AND A. J. LUCAS \\ Scripps Institution of Oceanography, La Jolla, California \\ E. SHROYER AND J. NASH \\ Oregon State University, Corvallis, Oregon
}

A. TANDON

University of Massachusetts Dartmouth, North Dartmouth, Massachusetts

J. T. FARRAR AND A. MAHADEVAN

Woods Hole Oceanographic Institution, Woods Hole, Massachusetts

(Manuscript received 29 March 2019, in final form 29 May 2020)

\begin{abstract}
The scale-dependent variance of tracer properties in the ocean bears the imprint of the oceanic eddy field. Anomalies in spice (which combines anomalies in temperature $T$ and salinity $S$ on isopycnal surfaces) act as passive tracers beneath the surface mixed layer (ML). We present an analysis of spice distributions along isopycnals in the upper $200 \mathrm{~m}$ of the ocean, calculated with over 9000 vertical profiles of $T$ and $S$ measured along $\sim 4800 \mathrm{~km}$ of ship tracks in the Bay of Bengal. The data are from three separate research cruises-in the winter monsoon season of 2013 and in the late and early summer monsoon seasons of 2015 and 2018. We present a spectral analysis of horizontal tracer variance statistics on scales ranging from the submesoscale $(\sim 1 \mathrm{~km})$ to the mesoscale $(\sim 100 \mathrm{~km})$. Isopycnal layers that are closer to the ML-base exhibit redder spectra of tracer variance at scales $\leqslant 10 \mathrm{~km}$ than is predicted by theories of quasigeostrophic turbulence or frontogenesis. Two plausible explanations are postulated. The first is that stirring by submesoscale motions and shear dispersion by near-inertial waves enhance effective horizontal mixing and deplete tracer variance at horizontal scales $\$ 10 \mathrm{~km}$ in this region. The second is that the spice anomalies are coherent with dynamical properties such as potential vorticity, and not interpretable as passively stirred.
\end{abstract}

\section{Introduction}

The stirring and mixing of properties by the oceanic flow field is of longstanding interest for understanding the dispersal and distribution of substances such as heat, salt, dissolved gases, nutrients, phytoplankton, and pollutants. Conversely, the patterns of chemical and

Supplemental information related to this paper is available at the Journals Online website: https://doi.org/10.1175/JPO-D19-0077.s1.

Corresponding author: G. Spiro Jaeger, gvsj@alum.mit.edu physical tracer distributions in the ocean can be used to interpret the dynamical characteristics of the flow. Within the vast range of spatial scales on which ocean currents and eddying motions act to stir properties, the submesoscale, and related dynamics, remain difficult to observe.

Submesoscale processes manifest at spatial scales $O(1-10) \mathrm{km}$, have time scales comparable to nearinertial waves, and play a key role in the vertical transport of properties, such as nutrients and buoyancy (Lévy et al. 2012; Thomas et al. 2008). They also facilitate the downscale cascade of energy through the loss of balance of mesoscale flows (Capet et al. 2008), thereby connecting 
the larger $O(100) \mathrm{km}$ mesoscale with the smaller $(<10 \mathrm{~m})$ dissipative scales. Observations of thermohaline compensation (Rudnick and Martin 2002), vorticity and divergence (Shcherbina et al. 2015), and the dispersion of drifters at fronts (D'Asaro et al. 2018; Essink et al. 2019), have shown the key role of submesoscale dynamics in controlling horizontal stirring and mixing within the surface mixed layer (ML). But, below the surface mixed layer, in what is classically considered the interior domain of isopycnal stirring, the role of submesoscale dynamics and forward energy cascades remains unclear (McWilliams 2016). Here, the effect of a downscale kinetic energy transfer on tracer variance, though seen in models of the submesoscale dynamical regime (Badin et al. 2011), has not been observed in the ocean.

Measurements of submesoscale dynamics have been stymied by the difficulty of synoptically observing a three-dimensional flow field in an area that is tens of kilometers wide, while resolving features that are a kilometer or subkilometer in extent and evolving on time scales of $O(1)$ day. Additionally, the kinetic and potential energy of such flows is dominated by internal gravity waves that mask the signal of vortical submesoscale dynamics (Callies and Ferrari 2013). Vortical motions are associated with anomalies in Ertel potential vorticity and evolve on time scales that range from subinertial to inertial. While recent studies have made progress in observing their submesoscale signatures (Thompson et al. 2016), challenges remain in directly measuring the submesoscale flow fields, which are responsible for stirring tracers. Oceanographers have instead examined the variability of tracer fields on isopycnal surfaces to infer the underlying dynamics (Kunze et al. 2015; Klymak et al. 2015).

We present a new look at along-isopycnal tracer variability on scales ranging from 1 to $100 \mathrm{~km}$, from a synthesis of data collected during three research cruises in the Bay of Bengal (BoB). This large basin in the northern Indian Ocean has the following characteristics: (i) it is strongly stratified in the upper $50 \mathrm{~m}$ by freshwater inputs; (ii) it contains distinct water masses, and hence, large-scale gradients of spice, a passive tracer; (iii) it hosts energetic eddies; and (iv) it is forced by both consistent winds and impulsive storms. It is thus a prime location for studying the dynamics of the upper ocean, both within the highly stratified pycnocline layers at the base of the mixed layer, and within the weaker pycnocline beneath.

Our analysis of these new observations of water mass distributions in the BoB reveals statistics inconsistent with existing descriptions of tracer stirring in the stratified ocean. The observed tracer gradient distributions within the shallow stratified pycnocline do not support quasigeostrophic or ageostrophic theories of homogeneous turbulence. The relative paucity of tracer variance below $10-\mathrm{km}$ scales compared to larger scales in our observations cannot be easily explained. We speculate that, most likely, submesoscale motions play a more important role than was previously envisaged in stirring tracer and dissipating its variance in the ocean's nearsurface interior, as has also been suggested by other studies recently (Yu et al. 2019; Siegelman et al. 2020).

In an accompanying study (Jaeger et al. 2019), we analyzed layered features in spice anomaly (water mass contrast) in the BoB and explained their formation by submesoscale processes. Here, we present the statistics of scale-dependent spice variance along isopycnal surfaces, which to a large extent, omits the effect of internal waves and is therefore viewed as a signature of alongisopycnal stirring. The relation between the layered intrusions of spice and along-isopycnal variance is discussed in Jaeger (2019).

In what follows, we begin by reviewing theories of ocean stirring (section 2). We then describe our new observations, with some details about the instruments and measurements in section 3. Our methods for parsing through the ship sections and constructing spectra of along-isopycnal tracer variance are described in section 4, and our statistical results are presented in section 5 . To provide context to our findings we compare the spectra calculated in the BoB to those from the Pacific and Atlantic Oceans (section 6), and provide potential explanations for the differences. We provide brief conclusions in section 7. Supplemental figures are included.

\section{Oceanic variance spectra}

Tracer gradients exist across a wide range of spatial scales in the ocean, from thousands of kilometers down to millimeters, and are connected by a downscale variance cascade (Smith and Ferrari 2009). Gradients are stirred, strained, and sharpened by motions ranging from the ocean gyres, eddies, and internal waves, to small enough scales where three-dimensional turbulence and molecular diffusion ultimately mix properties (Shcherbina et al. 2015). The large-scale currents, with scales $O(10) \mathrm{km}$ or more, are described by balanced subinertial quasigeostrophic $(\mathrm{QG})$ dynamics, which exhibits an upscale transfer of energy. At the smallest scales of $O(10) \mathrm{m}$ in the ocean interior, shear instabilities and breaking internal waves produce isotropic turbulence that effectively mixes tracers and erases tracer gradients and variance (MacKinnon et al. 2013). In between these scales, in the regime of submesoscale dynamics, wave dynamics, frontal instabilities, and vorticity 
containing modes are relevant (Polzin and Ferrari 2004; McWilliams 2016).

The typical scales of the motions stirring the ocean determine the distribution of the typical scales of tracer variance. The statistical distribution of tracer variance across these scales can be quantified by a spectral power decomposition $\mathscr{P}_{k}$ as a function of horizontal wavenumber $k$, providing a check on theories that attempt to describe the fluid dynamics, and a way to test the relative importance of QG and submesoscale dynamics in stirring the ocean. Unlike theoretical studies, observational studies often plot tracer variance spectra as gradient spectra $\mathscr{G}_{k}$ (multiplying $\mathscr{P}_{k}$ by $4 \pi^{2} k^{2}$ ), either because gradients are the directly measured quantity, or to be able to visually distinguish between variance spectral slopes more easily. We follow this convention, but in the text, we refer to variance spectra as power laws $\mathscr{P}_{k} \sim k^{m}$, and append the whitened gradient spectra power law $\left(\mathscr{G}_{k} \sim k^{m+2}\right)$ in parentheses to avoid misinterpretation.

Statistics of tracer patterns relate to statistics of the motions that create those patterns. The following descriptions (schematically shown in Fig. 1) are set in the framework of two-dimensional, homogeneous, stationary macroturbulence. Making the simplifying assumption for the existence of a turbulent inertial range between the forcing scale (e.g., the baroclinic Rossby radius of deformation) and the turbulent dissipation scale, the power spectrum for kinetic energy $E_{k}$ obeys several different power laws. The tracer's variance spectrum $\mathscr{P}_{k}$ is related to the kinetic energy spectrum $E_{k}$. We offer a brief summary of the tracer variance distributions predicted by different theories of ocean dynamics.

If $E_{k} \sim k^{-n}$, then in geostrophic turbulence theory, $\mathscr{P}_{k} \sim k^{(n-5) / 2}$ for $n<3$ (Callies and Ferrari 2013). QG theory for the ocean's interior predicts a kinetic energy spectrum $E_{k} \sim k^{-3}$ following a power law with $n=3$, and a tracer spectrum $\mathscr{P}_{k} \sim k^{-1}\left(\mathscr{G}_{k} \sim k^{+1}\right)$. If $n>3$, the kinetic energy spectrum falls off more rapidly, largescale motions dominate, and the nonlocal stirring leads to a Batchelor spectrum, $\mathscr{P}_{k} \sim k^{-1}$ (Batchelor 1959), equivalent to the interior $\mathrm{QG}$ tracer spectrum. Compared to interior QG dynamics, other dynamical theories, summarized below, predict relatively more kinetic energy at smaller scales. Dynamics that are relatively more energetic at smaller scales stir and eventually mix tracer more efficiently. They lead to relatively less tracer variance at smaller scales as compared to QG dynamics, resulting in the steepening of tracer variance spectra at smaller scales (Callies and Ferrari 2013).

This effect is restricted to the near-surface according to surface-QG (SQG) theory, which predicts steeper tracer spectra of $k^{-5 / 3}$ (gradient spectra $k^{+1 / 3}$ ) near the

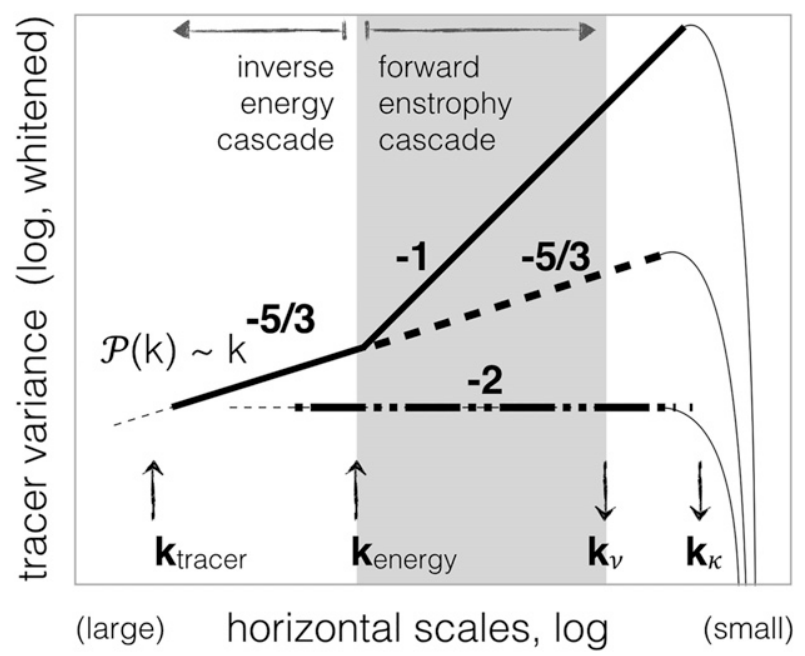

FIG. 1. Schematic of passive tracer spectral distributions $\mathscr{P}(k)$, whitened (multiplied by $4 \pi^{2} k^{2}$ ) for clarity of presentation, and shown on log-log axes. Predictions of spectral shapes of a tracer stirred by two-dimensional homogeneous turbulence, according to several theories: interior QG (solid), surface QG (dashed), stratified "pancake" turbulence (dashed), and frontogenesis (dash dotted). These predictions assume tracer variance in the ocean is introduced at the large scale (wavenumber $k_{\text {tracer }}$ ), cascades to smaller scales by the two-dimensional macroturbulence, and is destroyed by three-dimensional isotropic turbulent mixing. Energy is assumed to be injected at an intermediate scale ( $\left.k_{\text {energy }}\right)$ and cascades to larger scales in QG theory, producing a break in the predicted slope between the inverse energy cascade regime [where the kinetic energy spectrum $\mathscr{E}(k) \sim k^{-5 / 3}$, not shown], and the forward enstrophy cascade regime [where $\mathscr{E}(k) \sim k^{-3}$ ]. While energy falls off rapidly in the viscous inertial regime (wavenumber larger than $k_{\nu}$ ), passive tracer variance does not fall off until the diffusive regime (wavenumber larger than $k_{\kappa}$ ).

surface. But, being an extension of interior QG dynamics, the interior-QG spectrum still holds at greater depth, as the surface-enhanced small-scale motions are attenuated with depth (Lapeyre and Klein 2006). On the other hand, stratified turbulence theory also predicts the tracer variance spectrum to be steeper in the ocean's interior following an Obukhov-Corrsin spectrum with $k^{-5 / 3}$ (gradient spectra $k^{+1 / 3}$ ) (Brethouwer and Lindborg 2008). This is ascribed to stirring by turbulent patches with long-and-thin aspect ratios that form, for example, "blinis" or "pancakes" from the geostrophic adjustment of water patches mixed by breaking near-inertial waves (Sundermeyer et al. 2005). Last, frontogenesis and ageostrophic dynamics sharpen gradients into fronts more quickly; a series of sharp fronts yields a tracer variance spectrum with a $k^{-2}$ decay, and a flat $\left(k^{0}\right)$ gradient spectrum (Klein et al. 1998).

Even though precise predictions of spectral slopes emerge from the different dynamical theories, their robustness and relevance to actual ocean states is not 

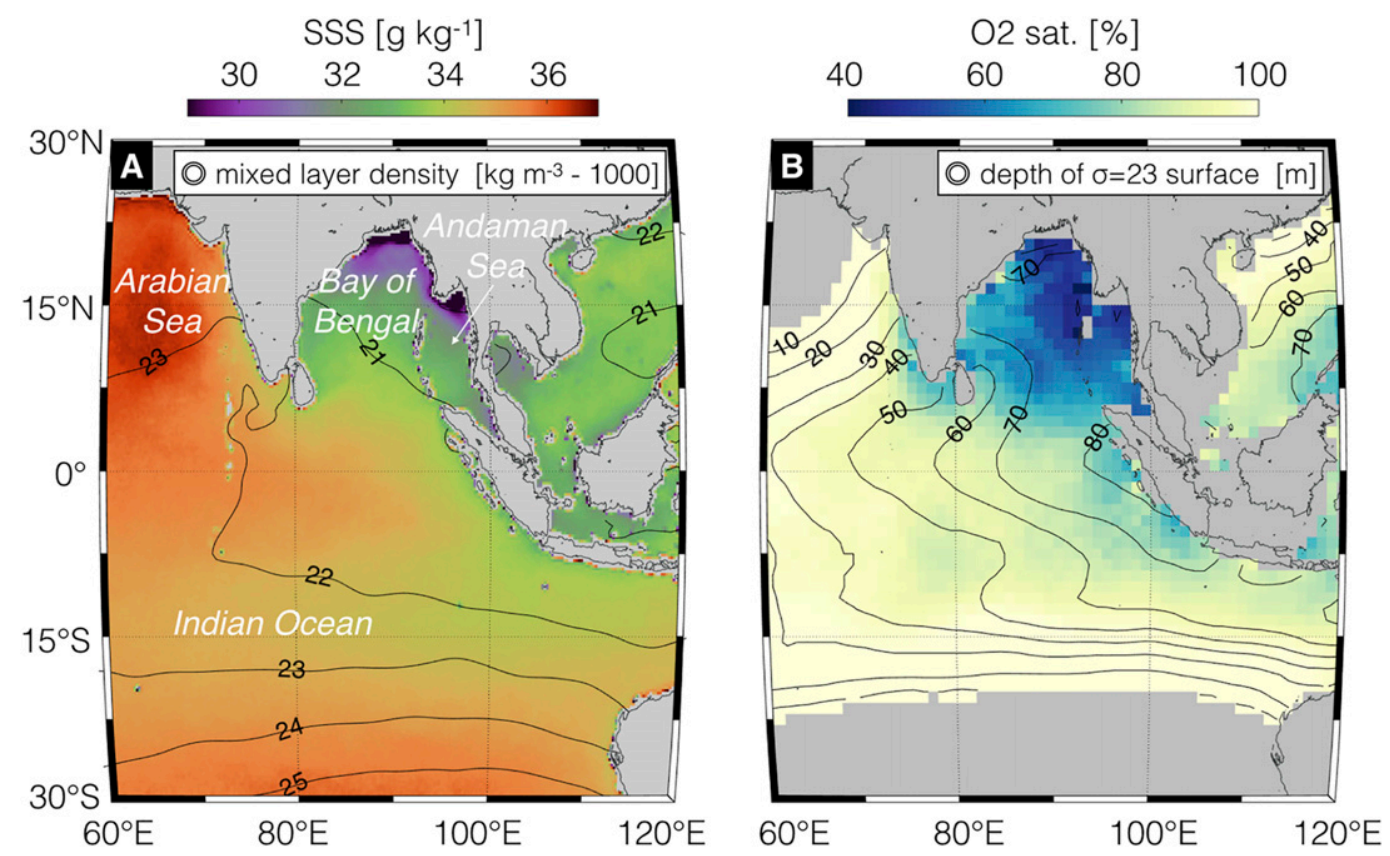

FIG. 2. Freshwater inputs lower the Bay of Bengal's surface salinity and strongly stratify the upper ocean, insulating a pronounced oxygen minimum zone (OMZ) below about 75-m depth. (a) Average surface salinity in 2017, measured by NASA's Soil Moisture Active Passive (SMAP) mission (Meissner et al. 2018). Contoured is climatological annual mixed layer density, from MIMOC (Schmidtko et al. 2013). (b) Climatological oxygen saturation at $1023 \mathrm{~kg} \mathrm{~m}^{-3}$ density $(\sigma=23)$ from World Ocean Circulation Experiment (WOCE). Contoured is the depth of the $1023 \mathrm{~kg} \mathrm{~m}^{-3}$ surface. At a mean depth of about $75 \mathrm{~m}$ in the Bay of Bengal, this density surface does not regularly outcrop in the bay. Low biological productivity compared to other OMZ regions suggests that the subsurface waters in the Bay of Bengal have long residence times with little ventilation.

certain. Theoretical tracer variance distributions are based on assumptions of an inertial range and statistical homogeneity of the flow field, yet it is not clear whether such idealized cascades exist, or whether they are disturbed by flow inhomogeneities such as coherent structures or persistent anisotropic currents, and energy inputs by instabilities across the submesoscale, topographic influence, bottom friction, or atmospheric forcing. Nonetheless, existing observational spectral studies (reviewed in the discussion) make frequent comparisons with the idealized theories, and observational spectra offer insights independent of testing predictions.

\section{Observations in the Bay of Bengal}

Our study uses hydrographic measurements to calculate statistics of tracer variance, analyzing the distribution of water mass anomalies. As part of two research programs supported by the U.S. Office of Naval Research, the Air Sea Interaction Research Initiative (ASIRI) and the ongoing Monsoon Intra-Seasonal Oscillations in the Bay of Bengal (MISO-BOB), the $\mathrm{R} / \mathrm{V}$ Roger Revelle and the R/V Thomas G. Thompson completed multiple hydrographic surveys of the Bay of Bengal between 2013 and 2018. Vertical profiles of temperature $T$ and salinity $S$ were measured to depths of at least $200 \mathrm{~m}$ during the ship surveys. Two of the surveys made transects $(>100 \mathrm{~km})$ with closely spaced $(\leq 300 \mathrm{~m})$ vertical profiles, while one survey completed longer transects $(>500 \mathrm{~km})$ that were sampled more coarsely $(\leq 5-\mathrm{km}$ spacing between vertical profiles), yielding a total of over 9000 profiles of $T$ and $S$.

\section{a. Environment}

The Bay of Bengal's unique hydrographic conditions are linked to the monsoonal circulation over the northern Indian Ocean, characterized by seasonally reversing winds and intense rainfall during the summer season. Both rainfall and river runoff contribute freshwater in excess of annual evaporation from the bay, lowering the surface salinity year-round (Fig. 2a), with the lowest values observed a couple of months after the wet season, when river runoff reaches a maximum (Sengupta et al. 2006). During subsequent winter months when surface cooling would be expected to lower the surface buoyancy enough to deepen the surface mixed layer, the low salinity of the surface mixed layer inhibits convective mixing and 

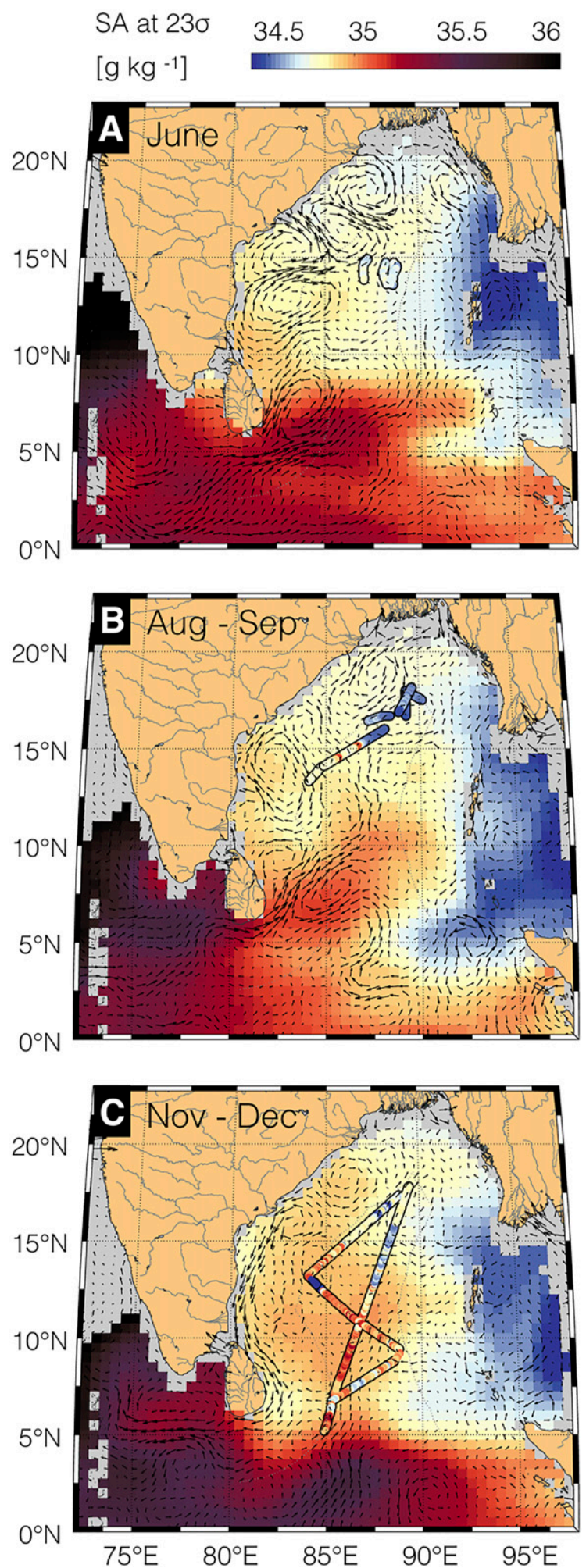

FIG. 3. The three research expeditions' tracks and the mesoscale currents at the time, along with climatological spice patterns. (a) 6-18 Jun 2018, (b) 24 Aug-20 Sep 2015, (c) 29 Nov-11 Dec 2013. Background colors show the climatological salinity on the $\sigma=23$ surface for each respective month(s) from MIMOC. The colored preserves the stratification (Jaeger and Mahadevan 2018), maintaining a deep chlorophyll maximum and strong vertical gradient in biogeochemical properties (Lucas et al. 2016; Shroyer et al. 2019). The salinitystratification limits the depth of wind-forced mixing throughout the year, isolating the subsurface layers of the Bay of Bengal from direct ventilation (Jinadasa et al. 2016). Seasonal wind-driven upwelling is observed only along the western boundary (Indian coast) during the southwest monsoon (Shetye et al. 1991).

Evidence of this persistent insulation is seen in the pronounced oxygen minimum zone below the surface (Fig. 2b), which exists even though the Bay of Bengal's surface primary production is not elevated compared to other tropical oceans (Fig. S1 in the online supplemental material). Shown in the same figure, oxygen saturation on a particular density surface $\left(1023 \mathrm{~kg} \mathrm{~m}^{-3}\right)$ shows a marked along-isopycnal contrast between the Bay of Bengal and the equatorial Indian Ocean to the south, indicating a relative lack of exchange between the basins and a long residence time of water in the interior of the BoB.

While ventilation of the interior via direct vertical exchange (wind-driven mixing, upwelling, or buoyancyloss driven convection) is weak (Prasanna Kumar et al. 2002), recent observational studies show subsurface eddies (Prasanna Kumar et al. 2004) advected from the Andaman Sea (Sarma and Udaya Bhaskar 2018; Gordon et al. 2017) to be a source of ventilation for the interior Bay of Bengal. Strong internal tides, internal waves, and subsurface mixing are observed over the shallow topography of the Andaman-Nicobar Submarine Ridge separating the Andaman Sea from the Bay of Bengal (Yi-Neng et al. 2012). The mixing in this region creates a fresher and colder water mass in contrast to the waters in the interior BoB (Fig. 3).

In addition to enhanced vertical salinity gradients above the thermocline, freshwater forcing also creates horizontal gradients in salinity, filling the BoB with both dynamic fronts in density, and passive (along isopycnal) contrasts between different water masses in the pycnocline (Gordon et al. 2016). Climatological subsurface isopycnal salinity fields are shown on an isopycnal

dots show the ship-observed salinity at the same density, for all sections longer than $100 \mathrm{~km}$. The black arrows show surface AVISO currents for a particular time period during each cruise. The basin-scale spice gradient is between salty warm water from the Arabian Sea and relatively fresh cold water, in the Andaman Sea. The western side of the Bay of Bengal hosts energetic mesoscale eddies of $O(100) \mathrm{km}$ scale, as well as seasonally reversing boundary currents. 
surface for 3 different annual periods during which in situ observations were taken (Fig. 3). The three expeditions took place in three different seasons: southwesterly winds and rain during the early summer and late summer monsoon marked the cruises from 6 to 18 June 2018, and from 24 August to 19 September 2015, while dry northeasterly winds of the winter monsoon (and one cyclone) prevailed during the first cruise from 29 November to 11 December 2013.

The subsurface salinity fields from MIMOC (Monthly Isopycnal and Mixed-Layer Ocean Climatology; Schmidtko et al. 2013), which is based primarily on Argo profiles, reveal the presence of both a salty (and relatively warm) water mass infiltrating from the Arabian Sea, and a fresh (and relatively cold) water mass leaking in from the Andaman Sea through channels in between the chain of Andaman and Nicobar Islands. The monthly climatological fields on the $1023 \mathrm{~kg} \mathrm{~m}^{-3}(\sigma=23)$ density surface exhibit persistent gradients between these end-member water masses. Compared to climatological salinity gradients, synoptic gradients are expected to contain higher variability at mesoscales. Indeed the expeditions sampled substantially fresher and saltier water and sharper gradients than the climatology in the interior of the bay. Mesoscale surface currents during the in situ observational period (based on AVISO sea surface topography) are dominated by eddies that are $O(100) \mathrm{km}$ in horizontal extent.

Climatological fields of subsurface salinity anomalies on isopycnal surfaces (compensated by temperature) display both an east-west gradient within the bay, and a north-south gradient in the southern bay (Fig. 3). The mean monthly patterns of salinity offer insights into time-mean subsurface flows, mirroring the spatial distribution of oxygen along this same density surface. Along the $\sigma=23$ surface at around 70-m depth, the higher salinity of the equatorial Indian Ocean infiltrates into the Bay of Bengal along its western margin, especially later in the summer. This increases the mean salinity and its gradients in the eastern BoB by winter, at which point the mean flow at the southern edge is southbound again. The meeting of distinct water masses in the upper $200 \mathrm{~m}$ of the Bay of Bengal make it an interesting site to study the processes affecting lateral tracer transport both within and below highly stratified ocean layers.

\section{b. Measurement of $T$ and $S$}

The 2013 survey used an Oceanscience UCTD Underway Profiling System (or Underway CTD system, or UCTD), measuring seawater conductivity, temperature, and pressure (Ramachandran et al. 2018). The profiler contains a battery-powered, internally recording
CTD, attached with a long line to a tail spool. During the long sections while the ship was underway at $\sim 8 \mathrm{kt}(1 \mathrm{kt} \approx$ $\left.0.51 \mathrm{~m} \mathrm{~s}^{-1}\right)$, the UCTD system was deployed in "free cast" mode. The probe is dropped over the stern and falls nearly vertically while unwinding line from its tail spool. On the deck, a winch pays out line to compensate for the ship's forward travel. Designed to fall through the water at approximately $4 \mathrm{~m} \mathrm{~s}^{-1}$, the probe's $\sim 60$-s fall time was set to reach a target depth of at least $200 \mathrm{~m}$ for all casts. Round-trip time is considerably longer $(\sim 10 \mathrm{~min})$ due to winch recovery and line rewinding time.

The 2015 and 2018 surveys used the "fast" conductivitytemperature-depth (FCTD) system, which was developed at Scripps Institution of Oceanography to collect rapid, real-time CTD profiles in the upper $2 \mathrm{~km}$ of the ocean (Pinkel et al. 2012). The subsurface package is composed of a streamlined profiler with a Seabird (SBE) 49 CTD and associated telemetry and control electronics, affixed to a load-bearing power and signal cable. The profiler is overboarded with a $\sim 10-\mathrm{m}$ boom to minimize contamination from the ship's wake, and retrieved utilizing a custom designed high speed winch. Winch controls are mainly automated, although watch-standers on deck and in the laboratory monitor the system at all times. Real-time CTD and profiler flight dynamics are collected and analyzed continuously. In the BoB, the FCTD was configured to collect profiles to 200-m depth while the ship was steaming at $4 \mathrm{kt} \mathrm{(2015)}$ and $2 \mathrm{kt}$ (2018). Profiler surface-to-surface round-trip time averaged roughly $3 \mathrm{~min}$, providing $300 \mathrm{~m}$ (or less) horizontal separation between profiles.

The UCTD and FCTD profiler's raw measurement of temperature and conductivity at $16 \mathrm{~Hz}$ and a fall rate of approximately 4 and $5 \mathrm{~ms}^{-1}$ yields between 3 and 4 samples per meter in the vertical. Before gridding in depth, salinity was calculated by combining the temperature and conductivity profiles with a small temporal offset based on a lagged correlation for each profile to eliminate salinity spiking artifacts (Thomson and Emery 2014). A vertically gridded, 1 decibar (approximately $1 \mathrm{~m}$ ) data product was formed by bin averaging, removing outliers with a median filter, and quality controlling each section, with special attention paid to the small fluctuations in salinity and temperature at depth. In several of the sections, the salinity-spiking correction removes abrupt, step-like horizontal changes in salinity between adjacent sections of profiles.

\section{c. Hydrography of the upper $200 \mathrm{~m}$}

The upper $200 \mathrm{~m}$ of the BoB are generally characterized by a shallow halocline transitioning into a deeper thermocline. Representative example profiles of $T, S$, and $T-S$ from each cruise are shown in Fig. 4, along with the aggregated $T-S$ profiles from all sections. This thermohaline 

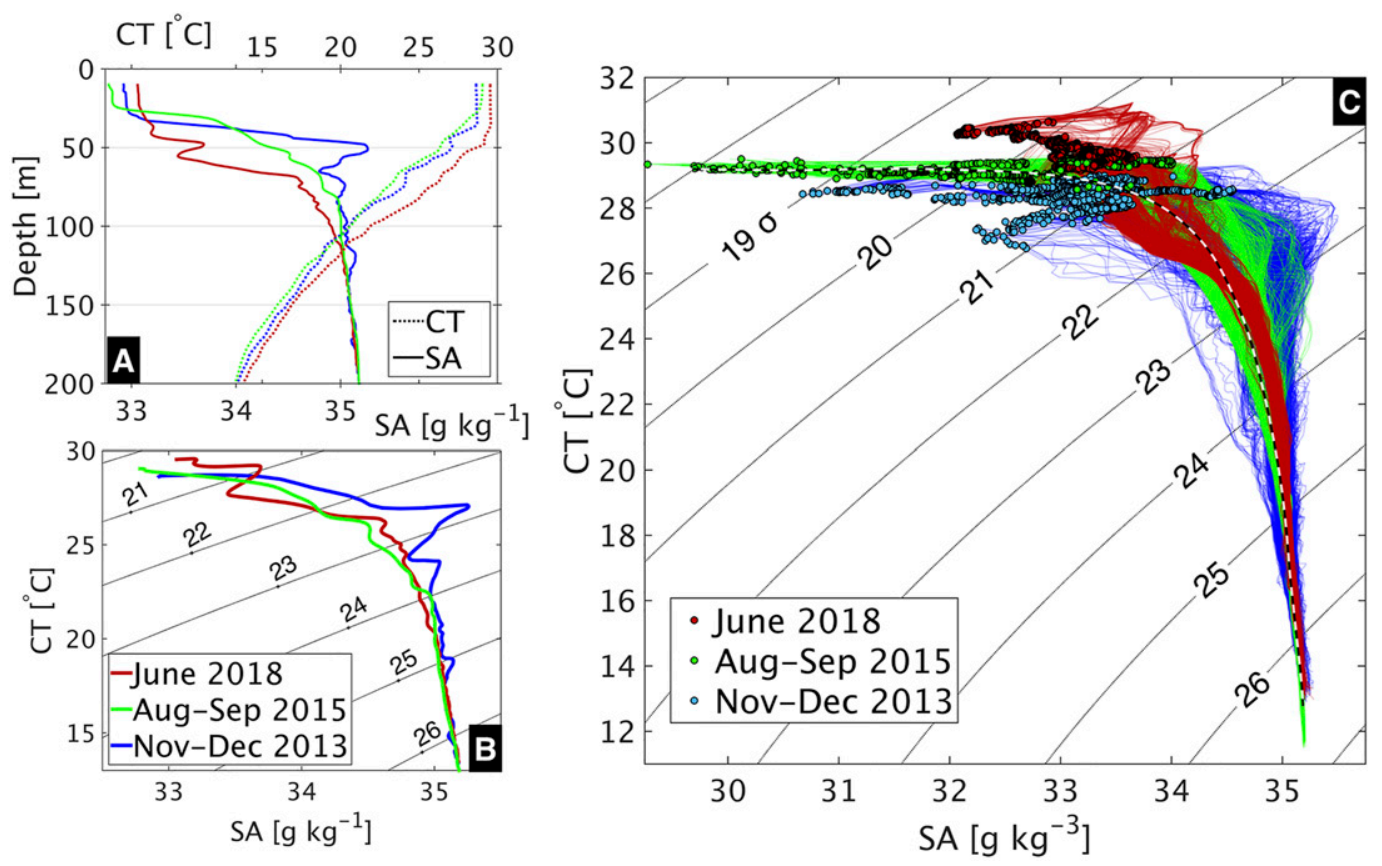

FIG. 4. The Bay of Bengal's upper ocean is characterized by a shallow sharp halocline above a deeper thermocline creating strong density stratification, and a subsurface layer of enhanced water mass variability. (a) Example profiles of Absolute Salinity (solid) and Conservative Temperature (dashed) from each cruise: June 2018 (red), August-September 2015 (green), November-December 2013 (blue). The vertical resolution of profiles is at least $1 \mathrm{~m}$. (b) Corresponding $T-S$ profiles. Thin curved contours show potential density referenced to the surface. (c) Plot of $T-S$ profiles measured on all 3 cruises. Circles mark surface mixed layer values. The dashed black-and-white line is a smoothed median $T-S$ profile from all cruises, used as the reference for calculating along-isopycnal spice (spicy and minty).

stratification leads to strong, sharp, and shallow density stratification, defined as the vertical gradient of buoyancy $\left[N^{2} \equiv-\left(g / \rho_{0}\right)(\partial \rho / \partial z)\right]$. Average $N^{2}$ profiles for each cruise, as well as the spread of density stratification encountered along the isopycnal surfaces $\sigma=21-26$, are shown in Fig. 5 . Average peak values of $N^{2} \sim 3 \times 10^{-3} \mathrm{~s}^{-2}$ (buoyancy frequency $N=0.04 \mathrm{~s}^{-1}$ ) were found at $25-\mathrm{m}$ depth during August-September 2015, and slightly deeper at $50 \mathrm{~m}$ during both the November-December 2013 and June 2018 surveys.

Stratification drops from a peak value of $N^{2} \sim 3 \times$ $10^{-3} \mathrm{~s}^{-2}$ in the sharpest pycnocline layers to $10^{-4} \mathrm{~s}^{-2}$ at $200-\mathrm{m}$ depth. Buoyancy frequency $N$ is typically 100 1000 times larger than the local Coriolis frequency $f \sim$ $3 \times 10^{-5} \mathrm{~s}^{-1}$. The $\sigma=21$ and 22 isopycnals are on average in the layer of maximum stratification forming the lower boundary of the ML (mean depths approximately 40 and $60 \mathrm{~m}$, mean $\left.N^{2} \sim 1 \times 10^{-3} \mathrm{~s}^{-2}\right)$. In 2018 the $\sigma=$ 22 isopycnal was always below the peak stratification, while in 2013 and 2015 it sometimes had stronger stratification than the $\sigma=21$ isopycnal above it. The $\sigma=23$, 24,25 , and 26 isopycnals are always in the interior pycnocline layers (mean depths are $70,100,130$, and $180 \mathrm{~m}$, respectively, mean $N^{2} \sim 0.1-0.5 \times 10^{-3} \mathrm{~s}^{-2}$ ).
While at 200-m depth there is very little $T-S$ spread across the three different seasons and years, there is considerable along-isopycnal $T-S$ spread at intermediate depths between approximately $50-100 \mathrm{~m}$, in between the $\sigma=22$ and 24 isopycnals. The 2013 survey, which had the largest geographic range, also had the largest range in $T-S$ variability along subsurface isopycnals denser than $\sigma=22$, measuring both the saltiest (warmest) and freshest (coldest) waters compared to water of the same density sampled in the smaller 2015 and 2018 surveys. The smallest $T-S$ variability was measured during the 2018 cruise, in which shorter ship tracks were sampled. The surface values show consistent differences between the different seasons. The warmest surface waters were seen in the early summer, the freshest in the later summer monsoon season, and the coldest in the winter season. Most surface mixed layer densities were lighter than $\sigma=21$, and no surface waters denser than $\sigma=22$ were encountered.

Water mass anomalies are defined as anomalies of Absolute Salinity $S_{\mathrm{A}}$ (or Conservative Temperature $\Theta$ ) (referred to hereafter as $S$ and $T$, respectively) from the average $S$ (or $T$ ) value along isopycnals calculated from all cruises. The salinity anomalies $\Delta S$, scaled by the haline 

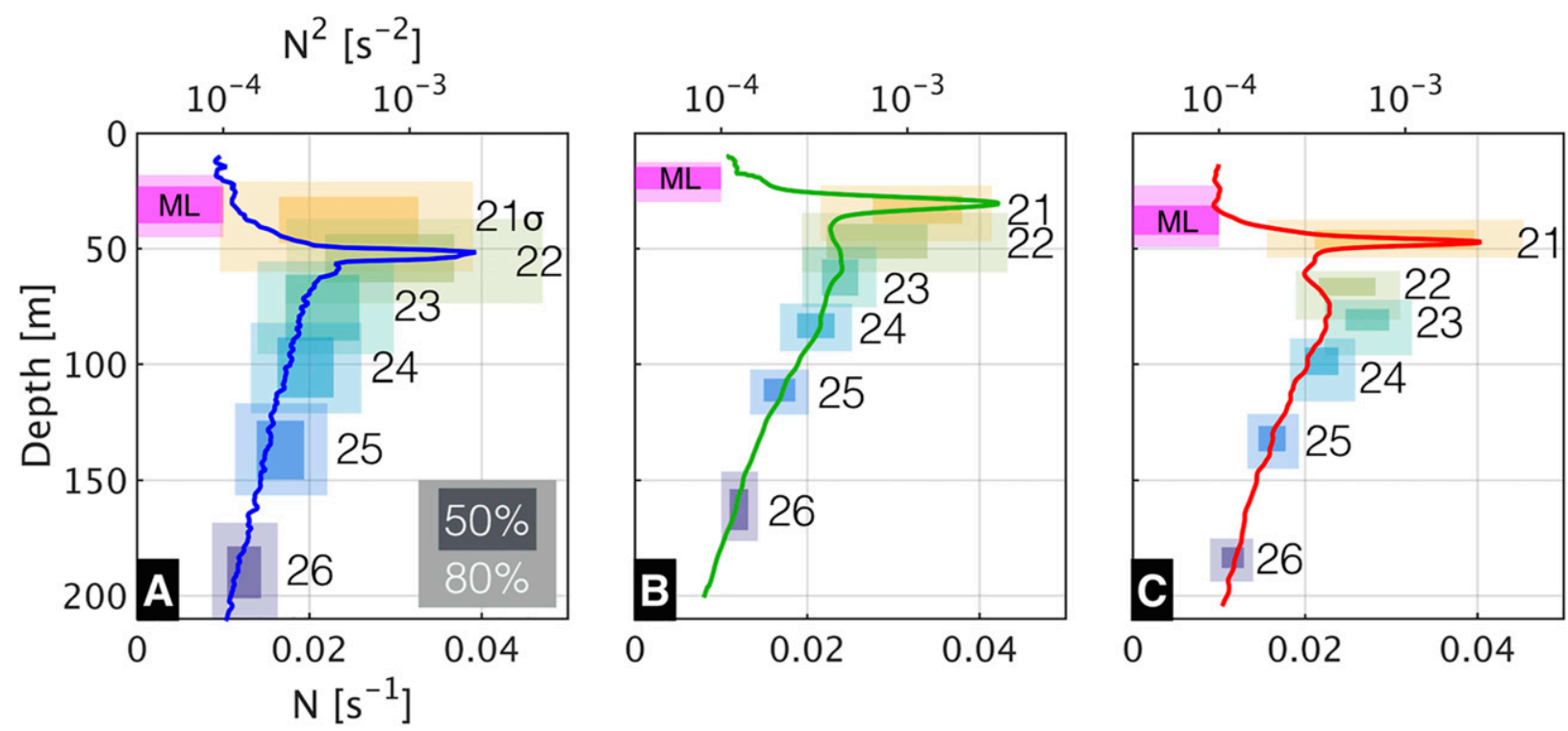

FIG. 5. Solid lines show the mean density stratification profiles: (a) November-December 2013, (b) August-September 2015, and (c) June 2018. To preserve the sharpness of the typical individual stratification profile, the average is calculated by first vertically shifting all individual profiles, such that their peaks align at the average depth of maximum stratification [average density level of peak $N^{2}: 21.9$ (2013), 20.7 (2015), 21.1 (2018)]. Shaded boxes show the distribution of depth and stratification at the isopycnal levels $\sigma=21-26$ (yellow to blue) during the three hydrographic surveys. The darker box covers the interquartile range of values, the lighter box covers the 10th-90th percentile of values. Similarly shown is the range of depth of the mixed layer (magenta).

contraction coefficient $\beta$, are equivalent to the temperature anomalies $\Delta T$, scaled by the thermal expansion coefficient $\alpha$, since by definition the anomalies must compensate each other's effect on density. The two components summed together, or equivalently, individually multiplied by two, define water mass or "spice" anomalies (Munk 1981). As long as there is a spread in $T-S$ values at the same density, water mass variability can be used as a passive tracer of seawater, since buoyancy gradients and dynamics are not affected by the particular values of $T$ and $S$, but only their combined effect on density. Though modified at the surface by input (and loss) of freshwater and heat, once subducted beneath the ML, a water parcel's $T-S$ properties are conserved as it is stirred on isopycnals, and changed only by interior mixing. Water mass variance forced at large scales cascades to smaller scales and is ultimately dissipated at the $3 \mathrm{D}$ turbulence scale. Furthermore, since we measure the lateral water mass gradients along isopycnals, the signal is unaffected by the heave and vertical strain caused by internal waves.

\section{Spectral analysis methods}

The vertical profiles of temperature and salinity were processed as follows to compute horizontal wavenumber spectra of water mass anomalies along density surfaces. Profiles of $T$ and $S$ were vertically interpolated onto an evenly spaced density profile with $0.1 \mathrm{~kg} \mathrm{~m}^{-3}$ increments, effectively producing measurements of spice along isopycnal surfaces for each section. The longest section from each cruise is plotted in Fig. 6, showing isopycnal spice anomalies. Since $S, T$, and spice anomalies along isopycnals are proportional to one another, we need use only one to calculate statistics. We use $S$ to be consistent with some of the previous literature (Kunze et al. 2015; Cole and Rudnick 2012). For each section that was approximately straight and longer than $100 \mathrm{~km}$ (all spice sections shown in Fig. S2), salinity anomalies along each isopycnal were horizontally linearly interpolated onto a regularly spaced distance grid with spacing smaller than the average profile spacing (2018: $100 \mathrm{~m}$, 2015: $300 \mathrm{~m}, 2013: 3 \mathrm{~km}$ ). Salinity along isopycnals $\sigma=$ 22 and 25 are shown in Fig. 7.

Spectra are calculated along each isopycnal using a fast Fourier transform (FFT) of detrended and Hanningwindowed segments. The Fourier coefficients are averaged over neighboring isopycnals less than $\pm 0.5 \mathrm{~kg} \mathrm{~m}^{-3}$ removed from the target isopycnals of $\sigma=21,22, \ldots, 26$, and further averaged in 10 logarithmically spaced wavenumber bins per decade $[k$ in cycles per kilometer $(\mathrm{cpkm})]$. For clarity of presentation, and to facilitate the visual differentiation between negative slopes, the plotted variance spectra $\mathscr{P}(k)$ are whitened by multiplying by $4 \pi^{2} k^{2}$, producing gradient spectra $\mathscr{G}(k)$. These steps are shown in Fig. S3 for the $\sigma=22$ and 25 isopycnals along the longest section from 2015 shown earlier. 

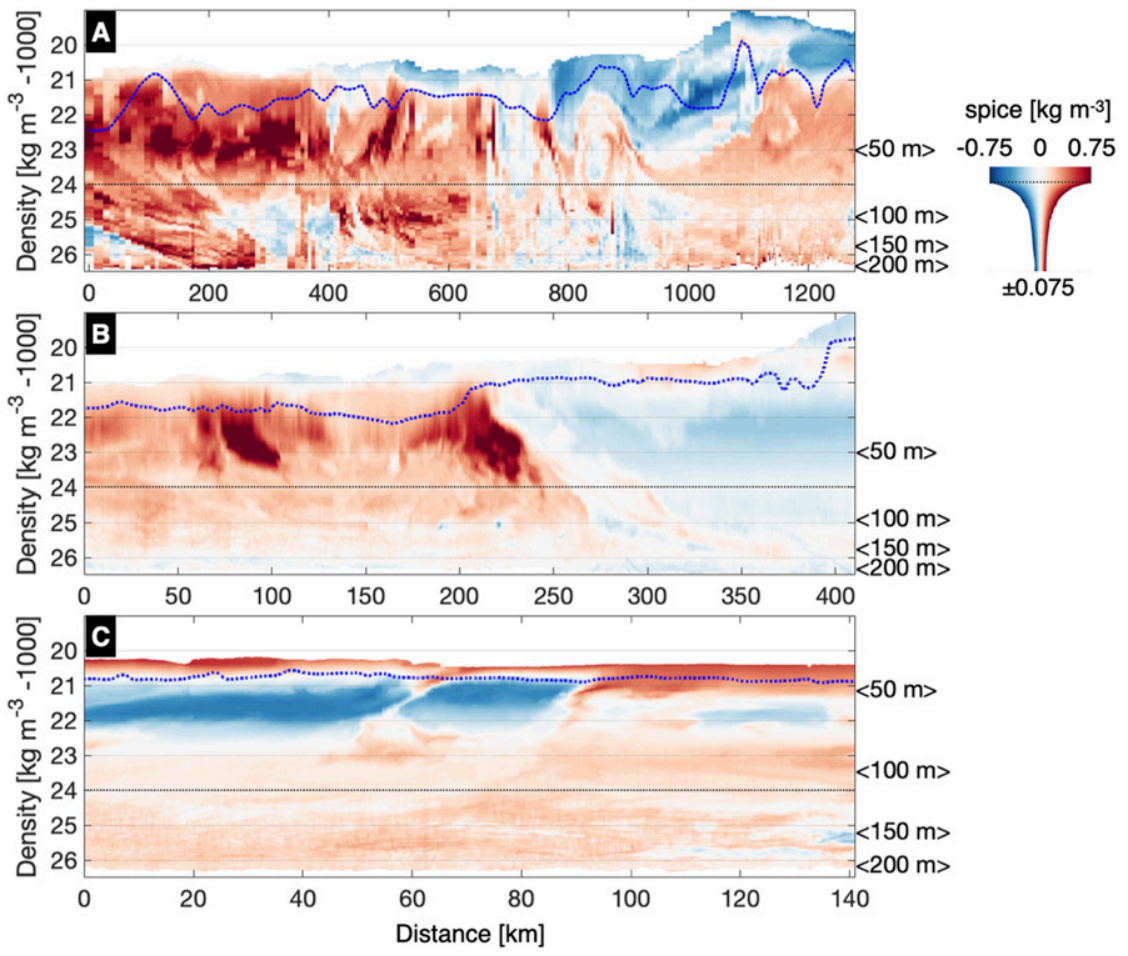

FIG. 6. Density vs distance sections of spice from cruises in the Bay of Bengal in (a) 2013, (b) 2015, and (c) 2018. Note the different horizontal scales. Spice (red = warm and salty, blue = cold and fresh) is defined as $\alpha \Delta T+\beta \Delta S$, the along-isopycnal density-compensated $T-S$ anomaly from the reference $T S$ profile shown in Fig. 4c. Note that below the $\sigma=24$ isopycnal (dotted line), the color values have been enhanced by a factor of up to 10 , as indicated in the color bar, to show the spice anomalies at depth that are an order of magnitude smaller than the shallower anomalies. Blue dashed line marks the density of maximum stratification $N^{2}$. On the right vertical axis are marked the isopycnal levels with average depths of 50, 100, 150, and $200 \mathrm{~m}$.

Following the procedure described in appendix A of Klymak et al. (2015), we have also applied a correction for variance lost at high wavenumbers due to finite sampling and horizontal gridding. The correction was determined empirically by making synthetic spatial series of a $k^{-2}\left(k^{0}\right)$ red-noise process, applying exactly the same nonuniform sampling as the profile spacing from the sections, interpolating onto a regular grid, and
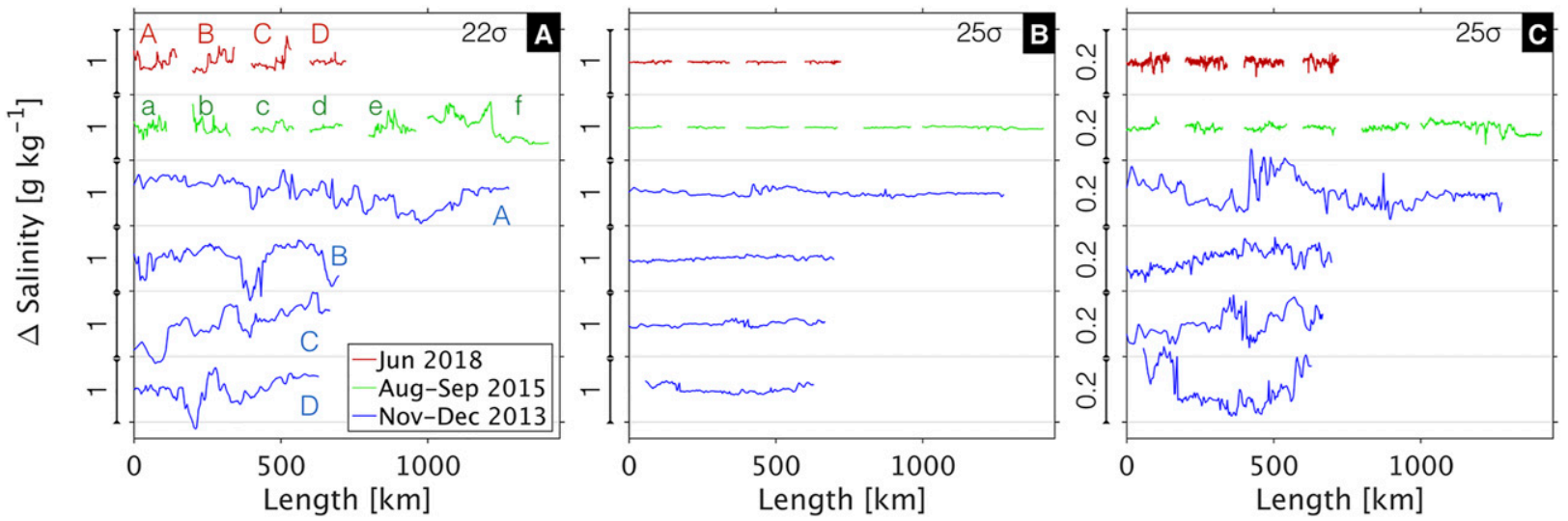

FIG. 7. Salinity (relative values, vertically offset) along all sections on (a) $\sigma=22$ and (b),(c) $\sigma=25$ isopycnals. All sections longer than $100 \mathrm{~km}$ (labeled A-F, shown in Fig. S2) from the 2018 (red), 2015 (green), and 2013 (blue) cruises. The vertical scale of (c) is reduced by a factor of 5 to show the weaker salinity fluctuations along this deeper isopycnal. 
calculating spectral estimates as described above. These estimates were then compared to spectra calculated from the full-resolution synthetic spatial series. The rolloff is consistent with the empirical transfer function $\operatorname{sinc}^{2}(\Delta x)$ with $\Delta x$ equal to the 0.67 times the mean separation between casts for each section. The correction is perhaps an overestimate for the shallower isopycnals, since it assumes an underlying red-noise $k^{-2}$ $\left(k^{0}\right)$ signal, whereas the observations at the fully resolved wavenumbers reveal an even steeper spectral fall-off of $k^{-3}\left(k^{-1}\right)$. Pseudocode of the spectral analysis and roll-off correction method are provided in the supplemental material.

For the 2013 large-scale survey cruise, with one section over $1000 \mathrm{~km}$ and three sections between 600 and $700 \mathrm{~km}$ long, and an average UCTD profile spacing of $3 \mathrm{~km}$, the spectral estimate is confined between wavelengths of $\sim 600$ and $\sim 10 \mathrm{~km}$. For the 2015 cruise with the longest section over $400 \mathrm{~km}$ long, but the other sections between 100 and $200 \mathrm{~km}$ long, and an average FCTD profile spacing of $0.3 \mathrm{~km}$, the spectral estimate is confined between wavelengths of $\sim 100$ and $\sim 1 \mathrm{~km}$. In contrast, during the 2018 cruise, the sections were sampled much more slowly, with $\sim 1 \mathrm{~m} \mathrm{~s}^{-1}$ ( $2 \mathrm{kt}$ ) ship speeds, still at least double the speed of currents below the ML, though of the same order of magnitude. Our sampling speed is $\sim 3$ times faster than the "slow" sampling tested in Rudnick and Cole (2011), which confirmed that spectral estimates from data collected along isopycnals with a slowly moving platform, such as a glider, are reliable with regards to internal wave aliasing problems, but might be affected by a "Doppler smearing" of features in wavenumber space. Since thermohaline features in the ocean are not frozen, but move during the time it takes a ship to sample them, there is an uncertainty in the true distance between sampled horizontal features. Given the mean current and shear magnitudes relative to the ship speed, measured lengths of features of $O(1-10) \mathrm{km}$ scales are estimated to differ from actual lengths at most by a factor of 2. This is treated as an uncertainty in wavenumber, but is relatively small given the logarithmic range of scales. Given the slower sampling, the spectral estimate from the 2018 data is confined between wavelengths of $\sim 30$ and $\sim 1 \mathrm{~km}$. The spectral slopes from the 2018 data are generally consistent with the spectral slopes in the same wavenumber range from the 2015 data, which were sampled at faster ship speeds.

The individual spectra for each section, along each of the 6 isopycnal levels $(\sigma=21-26)$ are shown in Fig. 8. While at some isopycnal levels ( $\sigma=23$ and 24) there is much variation between the spectra of individual sections (both between and within each of the 3 years), at isopycnal levels $\sigma=22$ and 26 the spectra are consistent across all sections. At these isopycnal levels the spectra from the three separate cruises are consistent with each other at overlapping scales, even though the three hydrographic surveys sampled different seasons in different years. They cover a 1-100-km range of horizontal wavenumbers, with the 2013 data resolving long wavelengths (circa $10-100 \mathrm{~km}$ ), the 2018 data resolving short wavelengths $(1-10 \mathrm{~km})$, and the 2015 data resolving the entire range $(1-100 \mathrm{~km})$. There are some differences in variance levels between the years, but the three datasets show the same general depth-dependent trends of decreasing variance levels and shallower spectral slopes with increasing depth. Given the large spread of spectral estimates among the 14 sections plotted, we only show confidence bounds for the combined mean spectral estimates calculated below.

For each tracer variance spectra corresponding to individual tracer sections in Fig. 8, power law slopes are estimated by a linear fit in log-log space over two scale ranges, from 10 to $100 \mathrm{~km}$ (2013 and 2015 data) and from 1 to $10 \mathrm{~km}$ (2015 and 2018 data). The individual slope estimates, the mean for each scale range, and the standard deviations are shown in Fig. 9. The uncertainty in slopes is dominated by the spread between sections, and not by the much smaller uncertainty in estimating the slope from each individual spectral estimate.

As an additional step, we calculate a mean spectral estimate for the entire BoB dataset along six density surfaces, combining the individual spectra from 2013, 2015, and 2018. To combine the individual spectra, they were first normalized by their variance levels at the wavenumber where they overlap $(0.1 \mathrm{cpkm})$, then wavenumber-bin averaged with a weight proportional to the length of the corresponding sections, and then multiplied by the average of their variance levels at $0.1 \mathrm{cpkm}$. These spectral estimates reflect a variance weighted average, based on measurements made along 14 sections that cumulatively span $4864 \mathrm{~km}$ of survey track, equivalent to $\sim 50$ independent segments of $100-\mathrm{km}$ length each. Given the spread in spectral slopes at some of the isopycnal levels, if the individual spectra sampled different physical regimes, the slope of the mean spectra are not necessarily an accurate representation of the true tracer distributions. This might be the case especially for intermediate-depth isopycnal levels $(\sigma=23$ and 24); however, the individual spectral slopes at shallower and deeper isopycnal levels $(\sigma=22$ and 26), at scales of $1-10 \mathrm{~km}$, are much more consistent with each other.

For these combined spectral estimates (Fig. 10), estimates of $90 \%$ confidence bounds are calculated with a chi-squared distribution following Klymak et al. (2015). Degrees of freedom are equal to the number of independent spectral estimates within each wavenumber bin. This is estimated as twice the number of squared Fourier coefficients that are averaged (by averaging over different 

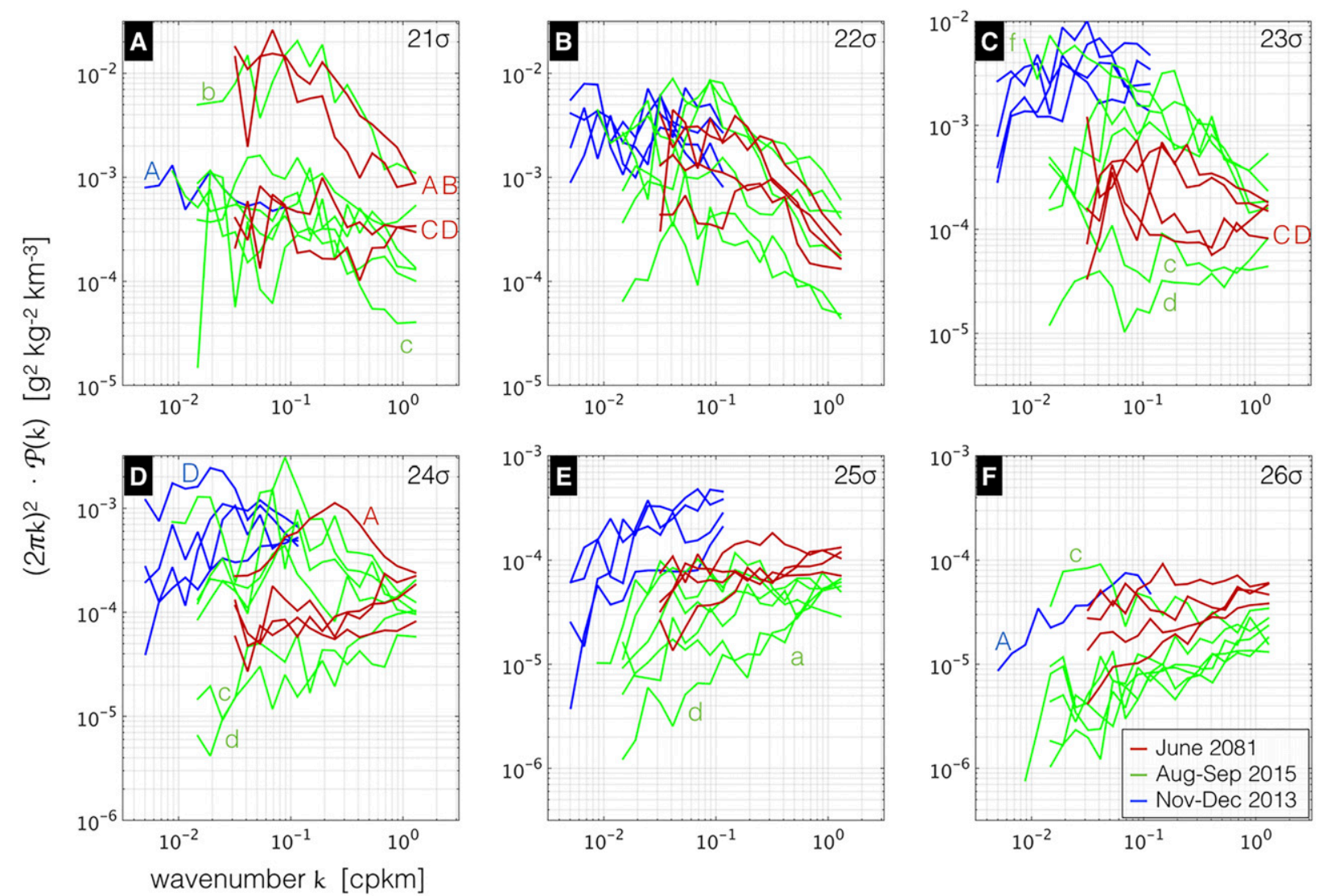

FIG. 8. Individual spectral estimates, frequency-bin averaged, along all sections longer than $100 \mathrm{~km}$ (particular letter labels refer to Fig. S2) during all cruises $($ red $=2018$, green $=2015$, blue $=2013)$, along the same isopycnals $(\sigma=21-26)$.

segments and over adjacent wavenumber bands) to form the estimate within each wavenumber band, reduced by an ad hoc factor (3) to be conservative. The sum accounts for coefficients from FFTs for all (9) isopycnal layers near each target isopycnal, but reduces this by an ad hoc factor (linearly increasing from 2 at the highest wavenumbers to 4 at the lowest wavenumbers) to account for the vertical correlation of anomalies between neighboring isopycnal layers. The wavenumber dependence of the factor is chosen in approximation of the results of Klymak et al. (2015), who found a scale-dependent vertical correlation. A visual inspection of salinity anomalies along neighboring isopycnals (Fig. S3) supports this approach, as large-scale anomalies seem more correlated than small-scale anomalies between nearby isopycnals. Furthermore, the signals of interest in the spectra, such as clear changes of slope, are much larger than the uncertainty estimate.

\section{Results: Tracer spectra}

The tracer spectra from the three expeditions offer a robust estimate of the variance distribution ranging from
$O(100)$ to $O(1) \mathrm{km}$ in the upper pycnocline of the BoB. Both the variance levels and the spectral slopes of variance distributions are depth dependent, with generally deeper isopycnals containing less variance and less red spectral variance slopes compared to shallower isopycnals. The salinity variance along isopycnals shallower than $100 \mathrm{~m}$ is most strongly elevated at scales of $10-100 \mathrm{~km}$, where the variance is two orders of magnitude greater than the variance along the deepest isopycnal at about $180 \mathrm{~m}$.

However, on the shallower isopycnals $(<100 \mathrm{~m})$, the elevated variance falls off steeply below $10-\mathrm{km}$ scales, with spectra along the $\sigma=22$ isopycnals exhibiting power laws $\mathscr{P}(k) \sim k^{-2.9 \pm 0.2}\left[\mathscr{G}(k) \sim k^{-0.9 \pm 0.2}\right]$ (Fig. 9). The $O(10) \mathrm{km}$ scale at which this change in spectral slope occurs coincides with the local Rossby radius of deformation in the surface mixed layer $\mathrm{NH}_{\mathrm{ML}} / f$ (Callies et al. 2016), where we estimate $N \sim 0.01 \mathrm{~s}^{-1}$ and $H_{\mathrm{ML}} \sim$ $30-50 \mathrm{~m}$ from the mean stratification profiles in Fig. 5. Coriolis frequency $f$ ranges from $1 \times 10^{-5}$ to $5 \times$ $10^{-5} \mathrm{~s}^{-1}$ depending on the latitude of the cruise track.

The steepening of the spectrum at scales smaller than circa $10 \mathrm{~km}$ (scales resolved in 2015 and 2018) is seen 


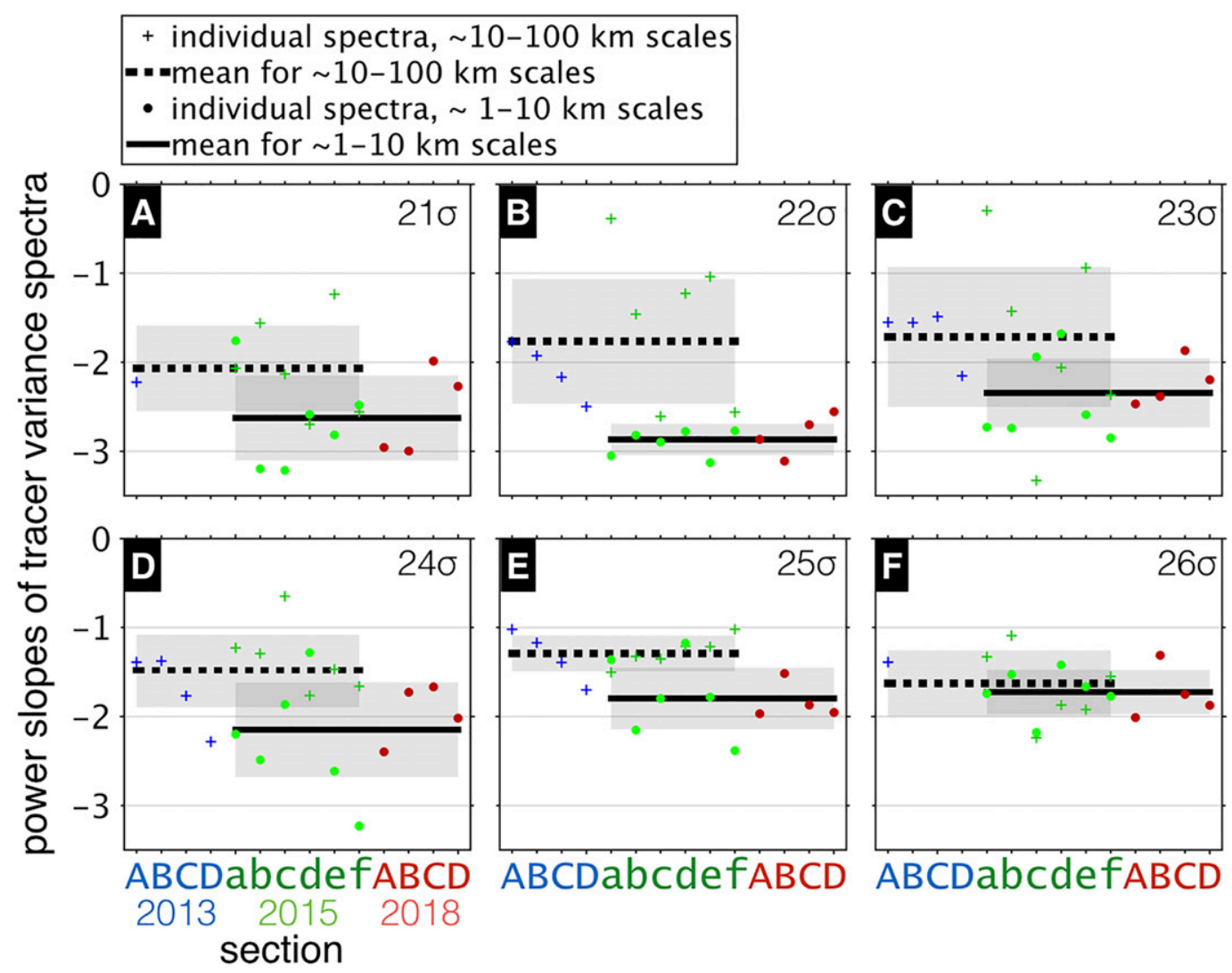

FIG. 9. Individual spectral slope estimates of all spectra in Fig. 8 for isopycnals $\sigma=21-26$. The crosses (blue $=$ 2013 , green $=2015)$ mark the spectral slope between scales of $O(10-100) \mathrm{km}$, the circles $($ green $=2015$, red $=2018)$ between scales of $O(1-10) \mathrm{km}$. The black lines mark the average slope over these two scale ranges, and shaded in gray is the standard deviation.

consistently along the $\sigma=22$ isopycnals, as well as along the $\sigma=21$ and 23 isopycnals for many sections, and along the $\sigma=24$ isopycnal along a few sections (Fig. 8). During the 2015 cruise the $\sigma=21$ and 22 isopycnals occasionally outcropped into the ML or into the weakly stratified layers in between the peak stratification depth and the ML base, yet the spectral steepening is also present along isopycnals that always remained at depths below the peak stratification, such as the $\sigma=22$ isopycnal in 2018 and the $\sigma=23$ isopycnal in 2015 (Fig. 5).

Salinity variance is in general highest along the shallowest isopycnal that is located within or just below the peak stratification. Salinity variance is reduced in some of the sections along the shallowest isopycnal $(\sigma=21)$, when it is located in weakly stratified layers above the peak stratification, such as during some of the 2013 and 2015 sections. This indicates that these weakly stratified layers are remnant mixed layers containing signatures of surface boundary forcing and variance dissipation.

A qualitative assessment by eye of the spice anomaly or salinity variance on isopycnals (Fig. 6 or Fig. 7) is consistent with the spectra that are calculated. For example, the salinity along the shallower isopycnals in the 100-km-long transects of the 2018 data has smallerscale fluctuations of lesser magnitude than the largescale variability seen in the longer sections from 2013 (i.e., a red gradient spectrum). Last, to complement the spectral analysis, the isopycnal salinity measurements were also analyzed using a wavelet decomposition. The results again show the same scale dependence of variance, with a lack of variance at $1-10-\mathrm{km}$ scales relative to $10-100-\mathrm{km}$ scales along the shallower isopycnals (Fig. S4).

\section{Discussion}

The observations of $T, S$, or spice variability analyzed in this study along isopycnals, are in some cases, associated with thermohaline intrusions or inversions in $T$ or $S$ (Ruddick and Kerr 2003). In Jaeger et al. (2019) we analyze the layers in spice that cross isopycnal surfaces and explain their formation. Our analysis suggests that double diffusion does not play a significant role in the formation of these layers, but frontal instabilities can 


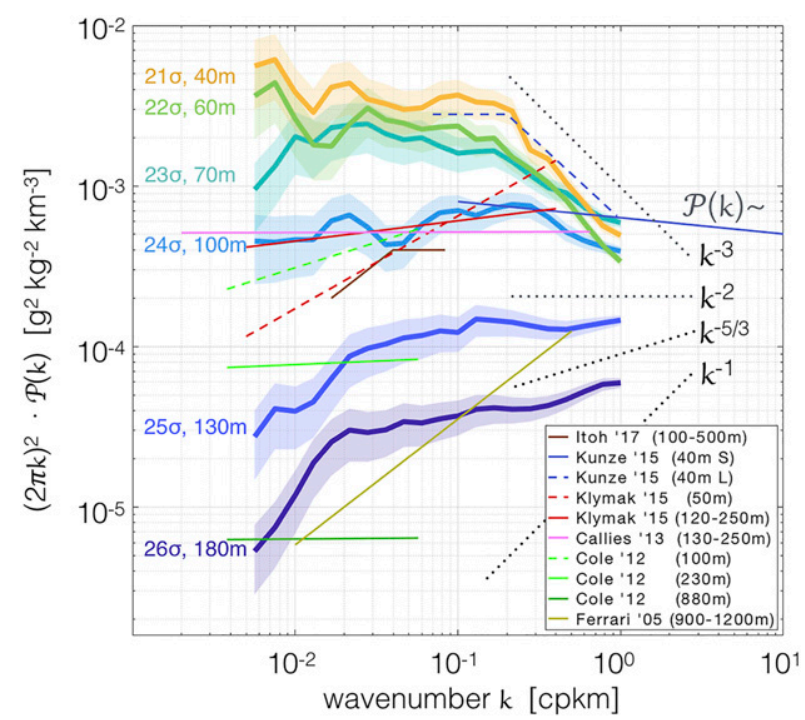

FIG. 10. Comparison of horizontal wavenumber variance spectra for salinity anomalies along isopycnals at different mean depths, from the Bay of Bengal (shaded areas represent confidence bound estimates as described in text). Thin straight lines depict spectra from other published studies: the CUGN project in the California Current System (Itoh and Rudnick 2017), the LatMix project in the Atlantic's Sargasso Sea (Kunze et al. 2015) and the NATRE project in the subtropical Atlantic (Ferrari and Polzin 2005), the Line P and IWAP cruises (Klymak et al. 2015), the Spice dataset (Callies and Ferrari 2013), and data from gliders (Cole and Rudnick 2012) in the subtropical and northern Pacific. Lines are graphical best fits of the slopes, converted to salinity anomaly spectra in wavenumber $k$ (cycles per kilometer) multiplied by $4 \pi^{2} k^{2}$. Dotted gray lines mark the whitened slopes of variance spectra $\mathscr{P}(k) \sim k^{m}$ with power laws of $m=-1$ (QG stirring), $-5 / 3$ (SQG/Obukhov-Corrsin), -2 (frontogenesis), and the observed decay of -3 of the shallow BoB spectra below $O(10) \mathrm{km}$.

generate intrusions or layering (Woods et al. 1986). Other types of dynamical instabilities could also create different sorts of lateral stirring environments at various depths, as described in Hua et al. (2013).

This study presents a robust set of passive tracer spectra from the relatively sparsely sampled Indian Ocean (Fig. 11), finding depth-dependent and scaledependent spectral slopes that are in part inconsistent with current theories of tracer stirring by ocean currents. We compare our results with the few other published studies of tracer spectra in the world oceans and discuss differences in environments and the potential role of submesoscale ocean dynamics that could explain the differences in the tracer spectra.

\section{a. Contextualizing the Bay of Bengal study}

There have been several studies in the Pacific and two in the Atlantic Ocean of the statistics of spatial distributions of spice, or compensated salinity or temperature anomalies along an isopycnal. We briefly summarize them here, and compare linear fits of their spectral slopes with our observations in Fig. 10.

Analysis of observations from the towed instruments in the "Spice" expedition (Callies and Ferrari 2013) and from repeated glider sections (Cole and Rudnick 2012) in the subtropical North Pacific at depths between 100 and $800 \mathrm{~m}$, consistently found isopycnal tracer spectra with $k^{-2}\left(k^{0}\right)$ behavior at $\sim 10-100$-km-scale wavelengths (Fig. 10). This depth-independent power law is inconsistent with both interior QG theory that predicts spectra to follow $k^{-1}\left(k^{+1}\right)$, as well as surface-QG modes that would predict steeper spectra below the surface.

Another recent analysis (Klymak et al. 2015) of profiler observations in the Gulf of Alaska (Line P) and undulating towed measurements in the subtropical Northern Pacific [Internal Waves Across the Pacific (IWAP)] also found tracer spectra between 10 - and $100-\mathrm{km}$ scales to be inconsistent with QG/SQG theory. They instead found power laws usually between $k^{-1.5}\left(k^{0.5}\right)$ and $k^{-1.7}\left(k^{-0.3}\right)$, and reddening toward $k^{-2}\left(k^{0}\right)$ along the deepest isopycnals at around $150 \mathrm{~m}$ along Line $\mathrm{P}$. While finding less red spectra than the previous studies, the observed reddening with depth trend is exactly opposite to the expected decay of SGQ modes and increasing dominance of interior-QG modes with increasing depth.

A wavelet analysis of glider data [California Underwater Glider Network (CUGN)] from the upper $500 \mathrm{~m}$ of the California Current System, resolving spectra over the narrow wavelength range of $12-60 \mathrm{~km}$, found a change in slope with scale in their isopycnal salinity gradient spectra (Itoh and Rudnick 2017). On average, across the seasons and inshore/offshore regions, they estimate a $k^{-1}\left(k^{+1}\right)$ slope in their "mesoscale" lower half range, and a $k^{-2}\left(k^{0}\right)$ slope in their "submesoscale" upper half range. They interpret the flat part of the spectrum, at scales smaller than the baroclinic Rossby radius, as the signature of sharp fronts.

A recent study (McCaffrey et al. 2015) applied a novel technique to the global Argo profile dataset, calculating salinity structure functions from scattered profiles instead of spectra along transects. They found equivalent isopycnal tracer spectra power laws of $k^{-1.7}\left(k^{0.3}\right)$ between 10- and 100-km scales, but with little dependence on depth in the upper $2000 \mathrm{~m}$. Their results are broadly consistent with the other mesoscale studies. The same structure function technique was also applied to a glider dataset from the open ocean in the northeast Atlantic [Ocean Surface Mixing, Ocean Submesoscale Interaction Study (OSMOSIS); Erickson et al. 2020]. They found little vertical variation in structure function slopes of passive tracers, with slopes equivalent to spectra power laws of $k^{-1.5}\left(k^{0.5}\right)$. However their results suggest significant transfer of submesoscale variability between the 


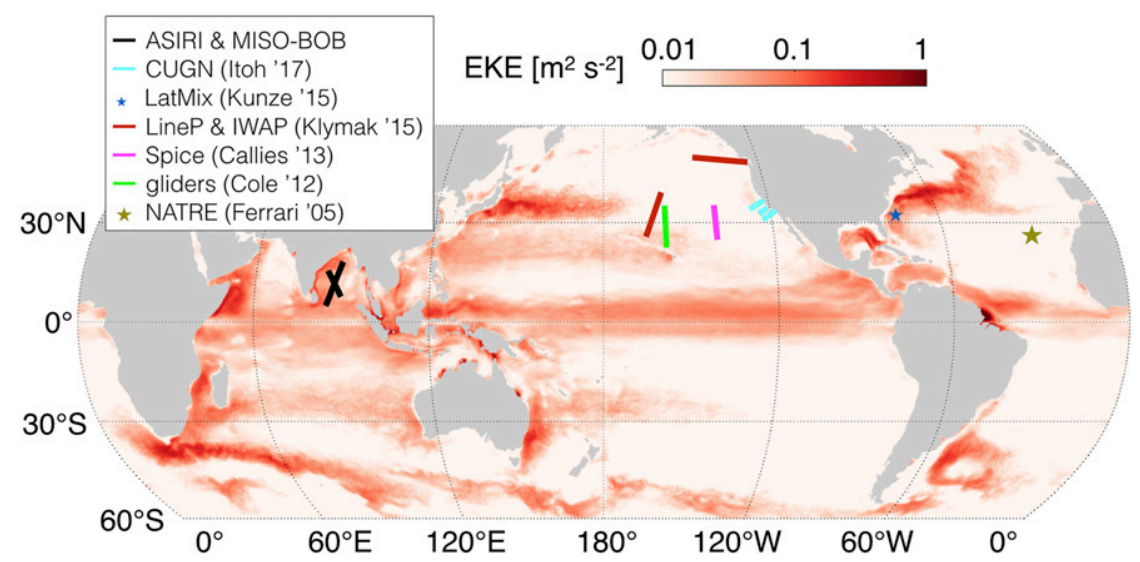

FIG. 11. Global map of eddy kinetic energy $=1 / 2\left(u^{\prime 2}+v^{\prime 2}\right)$ based on daily $0.25^{\circ}$ fields from the Global Ocean Gridded SSALTO/DUACS Sea Surface Height L4 product averaged from 2013 to 2017. Colored lines and stars show the location of studies reporting along-isopycnal salinity or temperature spectra, shown in Fig. 10. Note that only the LatMix study in the western Atlantic (blue star) was located in a similarly energetic region as the Bay of Bengal (black line).

surface ML and the interior occurs throughout the year, raising the importance of motions that stir at submesoscales in the interior.

In the subtropical Atlantic Ocean, the North Atlantic Tracer Release Experiment (NATRE) study (Ferrari and Polzin 2005) calculated structure functions from $T-S$ observations between 900 - and $1200-\mathrm{m}$ depth, finding equivalent isopycnal tracer spectra power laws of $k^{-1.2}$ $\left(k^{0.8}\right)$ between 2- and 100-km scales. Extending to smaller scales, the Lateral Mixing Directed Research Initiative (LatMix) study (Kunze et al. 2015) in the North Atlantic's Sargasso Sea found tracer spectral slopes again approximately equal to $k^{-2}\left(k^{0}\right)$ over wavelengths ranging from 10 to $0.03 \mathrm{~km}$ in the seasonal pycnocline between 20 - and $60-\mathrm{m}$ depth. However, measurements along a larger survey track [referred to as the Moving Vessel Profiler (MVP) and Triaxus surveys] that resolved wavelengths between 10 and $1 \mathrm{~km}$, found very red spectra estimated to lie between $k^{-3}\left(k^{-1}\right)$ and $k^{-2.5}\left(k^{-0.5}\right)$ in the 5-1.4-km wavelength band. Spanning less than a decade of wavenumbers, this estimate was deemed less robust than the main results of the study.

In summary, five of the six published studies found tracer gradient spectra with power laws close to $k^{-2}\left(k^{0}\right)$, inconsistent with QG predictions, but consistent with ageostrophic frontogenesis theory. The power law slopes were generally also independent of depth, or in some cases became less red toward shallower depths, in contrast to the SQG or surface-frontogenesis predictions of redder slopes near the surface. An exception is reported, albeit without stating a degree of confidence, in the LatMix dataset, which found a red gradient spectral slope between 5- and 1.4-km wavelengths, with the same $k^{-3}$ $\left(k^{-1}\right)$ power law that we report along shallow isopycnals in the BoB. Perhaps it is notable that both the BoB and the LatMix studies are in regions with elevated frontogenetic potential at the surface due to an energetic mesoscale, compared to the studies from the subtropical and northern Pacific. The BoB has a seasonal western boundary current that stands out in the climatological eddy kinetic energy (EKE) map (Fig. 11), with elevated EKE in the central BoB as well. The present study is also at lower latitudes $\left(5^{\circ}-18^{\circ} \mathrm{N}\right)$ than all the above cited studies of along-isopycnal tracer spectra (all located between $23^{\circ}$ and $50^{\circ} \mathrm{N}$ ). The present region's smaller Coriolis parameter leads to longer inertial periods and larger deformation scales.

One potential reason that the reddening of the spectral slopes reported here was not seen in previous studies could be that this is one of the few (if only) studies that measured lateral variations in temperature and salinity in the stratified region below the surface mixed layer at such fine horizontal resolution, and over such long distances and short time periods. The combination of vertical and horizontal resolution over vast distances helped to generate robust statistics. Furthermore, the large-scale contrast in spice along isopycnals provides a source for the spice variance in the BoB. The intense density stratification inhibits vertical mixing and preserves the signals of horizontal stirring. The possibility remains that the Bay of Bengal has unique mixing characteristics, at least compared to the oceanic settings of previous observations of spice distributions.

\section{b. Interpreting Bay of Bengal spectra}

The classical interpretation of wavenumber spectra of a passive tracer in the ocean interior assumes an injection (source) of tracer variance at large scales 
(small wavenumbers), a downscale cascade, and a sink of variance at small scales (large wavenumbers). If the statistics averaged over a large enough region are stationary, the variance level at any particular scale in between the forcing and the dissipative scales, depends on how efficiently gradients are strained into smaller features by the two-dimensional turbulence, and the dissipation rate of tracer variance through three-dimensional turbulent mixing. Tracer gradients in the interior can also retain signals from external forcing such as air-sea fluxes acting on the surface ML that are then restratified and entrained into the interior. Destruction of variance only occurs at the scale of three-dimensional isotropic turbulent mixing, which can act only on gradients at that scale. Within this framework, the slopes of isopycnal salinity spectra in the upper $200 \mathrm{~m}$ of the BoB at scales between 1 and $100 \mathrm{~km}$ tell a depth-dependent story with three parts.

First, at depths of $150-200 \mathrm{~m}(\sigma=26)$, the tracer variance level decays with increasing wavenumber following an approximately $k^{-1.7 \pm 0.3}\left(k^{0.3 \pm 0.3}\right)$ power law (Figs. $8 \mathrm{f}$ and 9f). This is in agreement with theories of stratified turbulence, which predict tracer variance distributions follow the Obukhov-Corrsin spectrum $\mathscr{P}(k)=C \chi \varepsilon^{-1 / 3} k^{-5 / 3}$, where $\chi$ is the turbulent temperature flux rate or dissipation rate, $\varepsilon$ the turbulent energy dissipation rate, and $C \approx 0.5$ is an empirical constant (Brethouwer and Lindborg 2008). Fitting the theoretical spectrum to observed variance levels, and assuming $\varepsilon$ is between $10^{-10}$ and $10^{-8} \mathrm{~W} \mathrm{~kg}^{-1}$, the temperature variance flux rate $\chi$ is predicted to be between $10^{-10}$ and $10^{-9} \mathrm{~W} \mathrm{~kg}^{-1}$. The observed spectral slope is also in agreement with predictions for tracer spectra stirred by two-dimensional geostrophic turbulence in an inverse energy cascade range above the stirring scale (Vallis 2017). However, it is unlikely that the dominant stirring at these depths is by motions or eddies of $O(1) \mathrm{km}$ or smaller; instead the deeper currents are due to the mesoscale eddy field. The slope is also in agreement with SQG predictions, which would necessitate surface modes to penetrate $150-200 \mathrm{~m}$ to the $\sigma=26$ isopycnal layer, even though this depth is clearly below the peak pycnocline and insulated from surface boundary forcing. Estimating the penetration depth $H$ by $(f / N) L \sim\left(3 \times 10^{-3} / 0.02\right) L$, $10-\mathrm{km}$-wide eddies would penetrate only $20 \mathrm{~m}$, while $100-\mathrm{km}$ eddies do reach $200 \mathrm{~m}$.

Next, at shallow depths of around 40-70 $\mathrm{m}(\sigma=22)$, the spectra also show an approximately $k^{-1.7 \pm 0.6}$ $\left(k^{0.3 \pm 0.6}\right)$ power law above $O(10) \mathrm{km}$ scales, but an unexpected finding is that they consistently steepen to $k^{-2.9 \pm 0.2}\left(k^{-0.9 \pm 0.2}\right)$ at scales smaller than $O(10) \mathrm{km}$ (Figs. $8 \mathrm{~b}$ and $9 \mathrm{~b}$ ). The $\sigma=22$ isopycnal surface is found both within and just beneath the depth of strongest stratification (Fig. 5). This change in slope at $O(10) \mathrm{km}$ scales suggests a change in dominant dynamics around the ML Rossby deformation radius $\left(\sim N H_{\mathrm{ML}} / f\right)$.

Finally, at intermediate depths of around $60-150 \mathrm{~m}$ $(\sigma=23-25)$, tracer variance spectra do not have a consistent slope between all 14 sections, but instead show a range of power slopes in between $k^{-1}$ and $k^{-3}$ (gradient spectral slopes between $k^{+1}$ and $k^{-1}$ ) (Figs. 8c-e and 9c-e). Some spectra at $\sigma=23$ and 24, isopycnals located always within the pycnocline, show similarly steep slopes as the spectra at $\sigma=22$. Spectral analysis does not identify what process is responsible for the steeper fall-off in tracer variance at scales below $O(10) \mathrm{km}$ and at stratified depths of up to $100 \mathrm{~m}$, or 3-4 times the ML depth.

The average of all spectra below $O(10) \mathrm{km}$ scales has a power law slope of approximately $k^{-2.0}\left(k^{0.0}\right)$, inconsistent with interior QG, somewhat less inconsistent with SQG or stratified turbulence predictions under idealized conditions, but consistent with other observational studies. It potentially indicates that mesoscale frontogenesis and ageostrophic dynamics cascade variance more rapidly than predicted by QG dynamics in the pycnocline (Klein et al. 1998). The on average redder slopes at these intermediate depths relative to the deeper $(\sigma=26)$ average spectrum is consistent with the notion that more small-scale stirring and straining increases the rate of downscale variance flux more at smaller scales along the tracer cascade, steepening the spectrum, and that ageostrophic small-scale motions attenuate over a shallower depth than geostrophic mesoscale currents.

However, the average of these spectra is not necessarily an appropriate measure if two distinct physical regimes are leading to two distinct tracer variance distributions, forming an approximately $k^{-3}$ power law spectrum at depths above about $70 \mathrm{~m}$, and an approximately $k^{-1}$ spectrum below 150 -m depths. While the literature regularly compares spectral observations with theory, the agreement or disagreement of tracer spectral slopes with theoretical predictions should be interpreted carefully. Predictions are made using idealized assumptions, such as homogeneity and scale separation, which allows an inertial range to form. These idealized conditions are unlikely to adequately represent the real conditions in the BoB, where for example kinetic energy might be input at various scales by ML instabilities and atmospheric forcing. More significant than observations of particular slopes are changes in spectral slopes, at particular scales, or between particular depths, indicating a 
change in the dynamics of the variance cascade. The observed steepening of the tracer variance spectra around scales of $10 \mathrm{~km}$ indicates a change in the ratelimiting process that transfers variance downscale.

\section{c. Potential explanations}

Might the unusual spectral slope of tracer variance observed along the shallower isopycnals simply be the signature of water mass anomalies subducted or injected into the interior from the surface ML? This explanation by itself seems unlikely, since we observe not an excess, but a lack, of variance at smaller scales. Such reduced levels of variance at relatively smaller $O(1) \mathrm{km}$ scales should be temporary, given the relative excess of variance present at larger $O(10-100) \mathrm{km}$ scales that could be cascaded downscale. We expect a downscale tracer variance cascade, whether described by QG or ageostrophic theory, to transfer variance across scales (from large to smaller spatial scales), within the time scale of the background mesoscale stirring and straining, which is of $O(10)$ days, given the mean $\mathrm{EKE}$ in the $\mathrm{BoB}$ of $O(0.1) \mathrm{m}^{2} \mathrm{~s}^{-2}$ and mesoscale eddies of $O(100) \mathrm{km}$ scale. Yet low oxygen levels (Fig. 2b) at the $\sigma=23$ isopycnal, which never outcropped in the BoB observations, suggest that water mass anomalies within this layer have residence time scales below the surface ML considerably longer than the time scale of stirring. Thus, if the deficit of 1-km-scale tracer variance along the $\sigma=23$ isopycnal is a remnant signature of mixing in the surface ML prior to water mass subduction, the small-scale variance should be replenished by a downscale variance cascade in the time since the water layer was last ventilated. The fact that small-scale variance is "missing," in layers that have been insulated from surface-forced mixing for a relatively long time, calls for a different explanation.

We are left with two categories of potential explanations, schematically represented in Fig. 12, and further discussed below. The observed steepening of tracer spectra below $10 \mathrm{~km}$ is either caused by (mixing) processes actively decreasing variance at scales below $10 \mathrm{~km}$, or by a suppression in the downscale spectral flux of variance below $10-\mathrm{km}$ scales.

\section{1) ENHANCED HORIZONTAL MIXING AT SCALES BELOW $10 \mathrm{KM}$}

We propose two candidates for adding effective mixing, which are not mutually exclusive, and could enhance tracer variance diffusion within the pycnocline and explain the steep decay of variance below $O(10) \mathrm{km}$. One is submesoscale frontal instabilities and associated submesoscale circulations that penetrate below the ML (input of energy, not necessarily

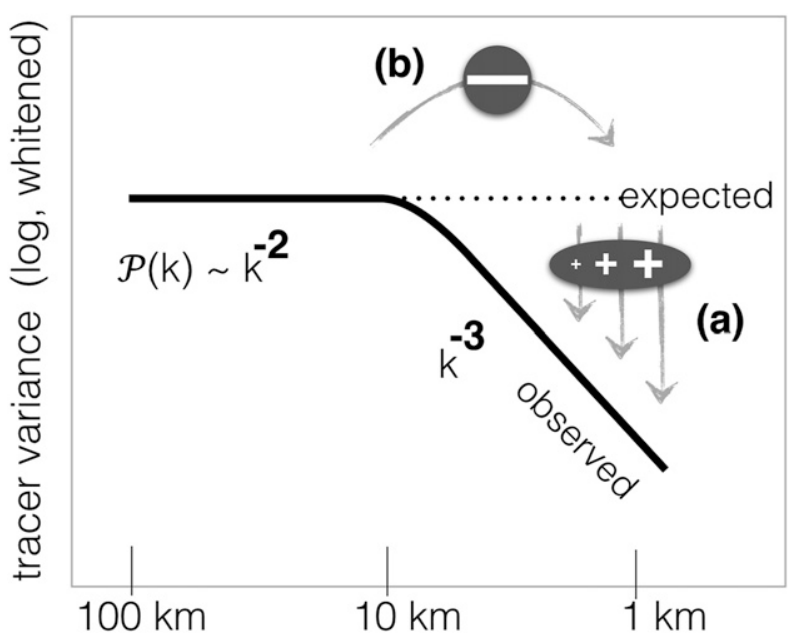

FIG. 12. Representation of the observed change in spectral slope of spice variance $\mathscr{P}(k)$ (whitened) along the shallower isopycnals in the $\mathrm{BoB}$, idealized from Fig. 10. Given the variance present at scales $O(10) \mathrm{km}$, we expect at least the same (whitened) variance level to be seen at smaller scales (dotted line), given any of the theories of two-dimensional stirring in a statistical steady state. Two potential explanations are suggested for the increasing deficit of tracer variance below $10-\mathrm{km}$ scales. Either (a) the $O(1) \mathrm{km}$ horizontal variance is destroyed by vertical mixing that is effectively felt at this horizontal scale, which is much larger than the three-dimensional isotropic mixing scale. Potential candidates are shear dispersion or submesoscale instabilities. Or (b) the downscale cascade of variance from larger scales is inhibited beyond $\sim 10-\mathrm{km}$ scales in the Bay of Bengal. A potential reason could be coherence between spice anomalies and dynamic anomalies, such that spice spectral distributions do not reflect stirring by homogeneous macroturbulence of an independent, stochastically distributed tracer, but rather the distribution of a dynamically relevant property.

water mass, into the stratified interior), while another is shear dispersion powered by near-inertial generated waves (NIW) with very small vertical wavelengths in the strongly stratified pycnocline. Both explanations would need to produce spice patterns with large aspect ratios (long and thin), such that turbulent vertical mixing effectively removes variance at submesoscales (Smith and Ferrari 2009).

Submesoscale instabilities convert the potential energy of lateral buoyancy gradients (usually but not exclusively in the ML) into kinetic energy, and through interactions with the mesoscale strain field, can transfer energy from the mesoscale to submesoscale and dissipative scales (McWilliams 2016). The surface ML of the $\mathrm{BoB}$ is characterized by strong density fronts with buoyancy gradients at least one order of magnitude stronger at scales of $O(1) \mathrm{km}$ compared to the mesoscale buoyancy gradients at scales $O(10-100) \mathrm{km}$ (Fig. 13). This ratio is calculated by comparing the largest magnitudes ( 1 and 0.1 percentile) of density 


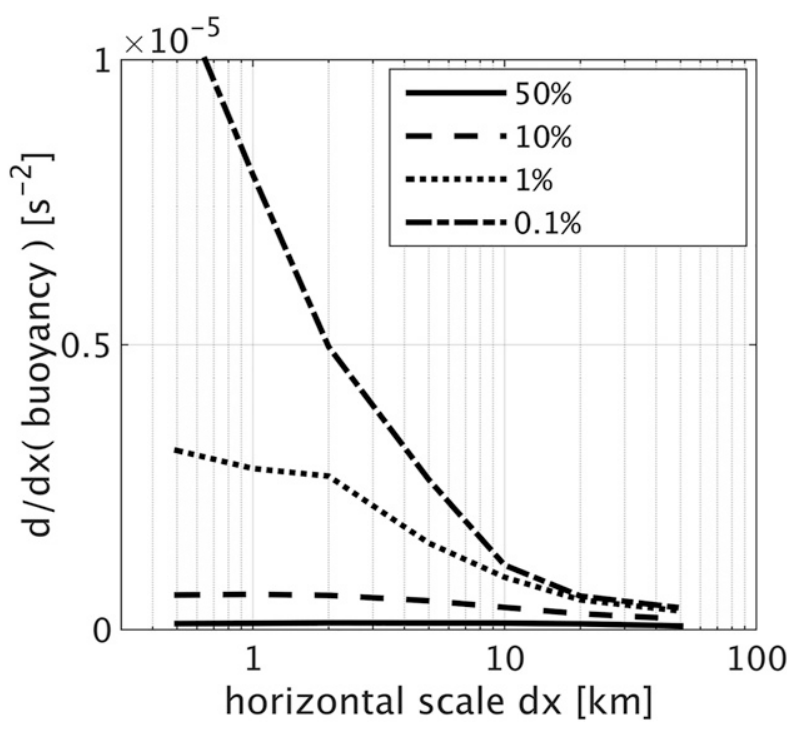

FIG. 13. The Bay of Bengal's surface mixed layer contains strong submesoscale density fronts. Magnitudes of buoyancy gradients $\left|\left(g / \rho_{o}\right)(d / d x) \rho\right|$ are calculated along the horizontal sections longer than $100 \mathrm{~km}$ from the 2015 survey and low-pass filtered (third-order Butterworth) with increasingly larger cutoff wavelengths. Colored lines show the top percentiles $(0.1 \%, 1 \%, 10 \%$, and $50 \%)$ of the buoyancy gradients, showing that the strongest fronts have widths below $O(1) \mathrm{km}$, and are at least one order of magnitude stronger than mesoscale gradients.

gradients in spatial transects smoothed by low-pass filters (third-order Butterworth) with cutoff wavenumbers ranging from equivalent wavelengths of $0.5-50 \mathrm{~km}$. Signatures of submesoscale frontal processes at $O(1-10) \mathrm{km}$ scales have been observed in the BoB (Ramachandran et al. 2018). ML eddies generated from baroclinic instabilities can also penetrate below the ML into the pycnocline, stirring water masses along isopycnals (Badin et al. 2011) and enhancing the effective lateral diffusivity at submesoscales.

The observed tracer variance fall-off below $10-\mathrm{km}$ scales along isopycnals that lie just beneath the ML, could be caused by enhanced stirring by submesoscale instabilities that are active within the mixed layer, powered by strong freshwater-controlled potential energy gradients or other sources of flow instabilities. The extra submesoscale stirring needs to act only at scales smaller than $O(10) \mathrm{km}$, reducing variance in the $O(1) \mathrm{km}$ band. The energy input by such submesoscale instabilities would invalidate the assumption of an inertial range by the theoretical slope predictions, and complicate interpretations of spectral slopes as related to rates of variance transfer.

The spectral fall-off could potentially also be due to shear dispersion enhancing effective along-isopycnal diffusivity. Internal-wave shear dispersion allows weak turbulent mixing at small scales to effectively diffuse lateral gradients at larger scales much more quickly than expected (Young et al. 1982). A sheared flow, whether or not reversible, tilts tracer isopleths to enhance the cross-diapycnal area of a water mass anomaly compared to its lateral (along-isopycnal) dimension, and amplify the weak but widespread vertical diffusion $K_{v}$ into a much greater lateral diffusion $K_{h} \sim\left(V_{z} / f\right)^{2} K_{v}$, where $V_{z}$ is the average vertical shear magnitude (Shcherbina et al. 2015).

Observations in the BoB reveal strongly sheared upper ocean currents dominated by shear layers of $O(10)$ m thickness, with an average vertical shear of magnitude $0.01 \mathrm{~s}^{-1}$ (Lucas et al. 2016; Shroyer et al. 2019). Given the small average Coriolis parameter in the BoB of $f=3 \times 10^{-5} \mathrm{~s}^{-1}$, the effective isopycnal diffusivity is enhanced by a factor of $10^{5}$ over the diapycnal diffusivity. However, observations in the BoB show weak turbulence below the ML, with median values of the diapycnal diffusivity $K_{v}=10^{-6} \mathrm{~m}^{2} \mathrm{~s}^{-1}$ in the pycnocline, interspersed with sporadic elevated values of up to $10^{-3} \mathrm{~m}^{2} \mathrm{~s}^{-1}$ in the upper $50 \mathrm{~m}$ (Shroyer et al. 2016; Lucas et al. 2016). Thus the average effective lateral diffusivity is estimated to be $O(0.1) \mathrm{m}^{2} \mathrm{~s}^{-1}$ below 50-m depth, similar to other estimates, yet an order of magnitude smaller than what was estimated from dye-release experiments in the coastal ocean south of Martha's Vineyard (Sundermeyer and Ledwell 2001) and in the Sargasso Sea (Shcherbina et al. 2015). However, within the top of the shallow pycnocline, right below the ML, vertical diffusivities of $K_{v}=10^{-5} \mathrm{~m}^{2} \mathrm{~s}^{-1}$ do not seem unreasonable, and thus lateral diffusivities $K_{h}$ could be enhanced to values of $O(1) \mathrm{m}^{2} \mathrm{~s}^{-1}$. In addition, if enhanced vertical shear is correlated with intermittent enhanced turbulent mixing (Kunze and Sundermeyer 2015), effective lateral mixing could intermittently be an order of magnitude larger.

If shear dispersion in the $\mathrm{BoB}$ is driven by near inertial waves, which generate oscillatory shear, the spatial scales over which the effective diffusivity acts is equal to the spatial scales of the oscillation's lateral excursions. This scale is estimated as $\Delta z V_{z}(1 / f)$, where $\Delta z$ is the vertical scale of the oscillation. Given a shear of $0.01 \mathrm{~s}^{-1}$ across $10-\mathrm{m}$ thick layers, the horizontal scale is $O(1) \mathrm{km}$. It is thus plausible that on the shallowest isopycnal surfaces in the top $100 \mathrm{~m}$ of the $\mathrm{BoB}$, shear dispersion, acting on lateral gradients of $O(1) \mathrm{km}$ scales, enhances isopycnal diffusivity to $O(1-10) \mathrm{m}^{2} \mathrm{~s}^{-1}$. This would effectively reduce tracer variance at submesoscales, and potentially lead to the steep spectral fall-off, perhaps aided by the low latitude and high stratification of the BoB that favor strong NIW shear layers with very thin vertical extent. 


\section{2) INHIBITED CASCADE OF COHERENT WATER MASS ANOMALIES}

A reduction in the downscale cascade of tracer variance from larger scales could also explain the steepened spectral slope of spice variance below $10-\mathrm{km}$ scales. One way for this to occur is if the tracer distribution is correlated to the flow field in a manner that the eddy stirring and straining is ineffective at breaking apart the tracer's $10-100-\mathrm{km}$ scale patterns. For example, the tracer distribution could be modulated by coherent structures in the flow, or correlated with potential vorticity (PV) anomalies formed by past subduction or entrainment of water masses from the surface or frictional bottom (lateral) boundary layers. In such a case, the assumption that macroturbulence is stochastic and homogeneous is invalid. Both in 2013 and 2015, we encountered mesoscale eddies with an anomalous fresh cold water mass visible in the core (Fig. S2), and reported in (Gordon et al. 2017), while on a smaller scale, submesoscale subduction was seen to create anomalous stratification and water mass anomalies at fronts (Ramachandran et al. 2018). Another possible mechanism correlating water mass anomalies with PV is cabbeling. If the spice contrast across a compensated $T-S$ front is large enough, isopycnal mixing leads to an increase in density, generating small-scale vertical mixing (Thomas and Shakespeare 2015). Occurring within strong stratification, this process would create thin, well-mixed, low-PV regions with distinct $T-S$ characteristics. Further investigation into the viability of this potential $\mathrm{PV}$-spice coherence creation mechanism is needed.

If the observed steep spectral slope is indeed due to an inhibited spice variance cascade, then water mass distributions in the $\mathrm{BoB}$ are not a measure of a random passive tracer being isopycnally stirred, but rather a tracer that, though strictly passive, is correlated with dynamical properties and coherent flow structures. However, even if currents are partially correlated with water mass anomalies, the propagating mesoscale eddy flow field would still be expected to encounter uncorrelated tracer gradients of $O(100) \mathrm{km}$ scales, and strain these to $O(1-10) \mathrm{km}$ scales, thereby replenishing the missing variance levels along isopycnals in the interior.

\section{Concluding remarks}

We present a synthesis of along-isopycnal spice variance measured from three cruises in the Bay of Bengal and find that along isopycnals in the strongly stratified upper $75 \mathrm{~m}$, the tracer variance spectra are much more steeply sloping $\left[\mathscr{P}(k) \sim k^{-3}\right]$ in the submesoscale regime than can be explained by existing theories of two-dimensional macroturbulence. The lack of spice variance at $1-10-\mathrm{km}$ scales relative to the variance levels at $10-100-\mathrm{km}$ scales means that the horizontal gradients between warm-salty and cold-fresh features are too smooth between 1- and 10-km scales to be consistent with QG or frontogenetic dynamics. This indicates that in this regime, either horizontal mixing is more effective than expected, or water mass anomalies are less effectively stirred and strained into 1-km scale features. The first, more likely, explanation invokes the importance of submesoscale processes for horizontal mixing, whether they be vortical or wavelike in nature. Enhanced shear dispersion by NIWs with very small vertical wavelengths is a promising candidate. The latter explanation would mean that spice spectral distributions do not reflect stirring by homogeneous macroturbulence of an independent, stochastically distributed tracer, but rather the distribution of a dynamically relevant property.

At depths between 100 and $200 \mathrm{~m}$, the flattening of spectra suggests that tracer stirring dominated by frontogenesis $\left[\mathscr{P}(k) \sim k^{-2}\right]$ transitions toward stirring driven by stratified turbulence or SQG dynamics $\left[\mathscr{P}(k) \sim k^{-5 / 3}\right]$ with depth. These findings differ from similar observational studies in the Atlantic and Pacific Oceans, which did not observe the steep tracer spectra in the submesoscale range, nor the significant flattening of spectra with increasing isopycnal depth. The results attest to the strong stratification and separation between processes stirring the upper $40-70 \mathrm{~m}$ of the pycnocline, the intermediate layers around $100 \mathrm{~m}$, and the more quiescent interior around $200 \mathrm{~m}$.

The results from this study demonstrate that twodimensional macroturbulence in the ocean is not yet completely understood. The lack of 1-km-scale variance calls attention to the potential role of submesoscale dynamics and near-inertial waves, or their interactions, in controlling horizontal mixing in the upper ocean, and to potential misinterpretations of spice anomalies. A proper accounting of submesoscale and wavelike oscillatory processes is important for the development of model subgrid parameterizations.

Acknowledgments. We are grateful to the captain and crew of the R/V Roger Revelle and the R/V Thomas $G$. Thompson, and all ASIRI-OMM and MISO-BOB scientists. We thank Prof. Andrew Thompson and an anonymous reviewer for suggestions that improved the manuscript. This work was carried out under the Office of Naval Research's Air-Sea Interaction Regional Initiative (ASIRI) and Monsoon Intra-Seasonal Oscillations in the Bay of Bengal (MISO-BOB) research initiatives, in collaboration with the Indian Ministry of Earth Science's Ocean Mixing and Monsoons (OMM) initiative supported 
by the Monsoon Mission. Support came from ONR Grants N00014-16-1-2470, N00014-13-1-0451, N00014-17-1-2390 (G.S.J. and A.M.), N00014-14-1-0455 (J.M. and J.N), N00014-17-1-2511 (J.M.), N00014-13-1-0489, N00014-17-12391 (A.L.), N00014-15-1-2634 (E.S.), N00014-13-1-0456, N00014-17-1-2355 (A.T.), and N00014-13-1-0453, N0001417-1-2880 (J.F.). All authors declare that they have no competing interests.

Data availability statement. All data needed to evaluate the conclusions in the paper are present in the paper and/or the supplementary materials. Additional data related to this paper may be requested from the authors.

Used in Fig. 2, SMAP salinity data are produced by Remote Sensing Systems and sponsored by the NASA Ocean Salinity Science Team. Data are available at www.remss.com. Used in Fig. 3, the altimeter products were produced and distributed by Aviso+ (www.aviso.altimetry.fr), as part of the Ssalto ground processing segment. Used in Fig. 11, the Ssalto/Duacs altimeter products were produced and distributed by the Copernicus Marine and Environment Monitoring Service (CMEMS) (www.marine.copernicus.eu).

\section{REFERENCES}

Badin, G., A. Tandon, and A. Mahadevan, 2011: Lateral mixing in the pycnocline by baroclinic mixed layer eddies. J. Phys. Oceanogr., 41, 2080-2101, https://doi.org/10.1175/JPO-D-1105.1.

Batchelor, G. K., 1959: Small-scale variation of convected quantities like temperature in turbulent fluid. Part 1. General discussion and the case of small conductivity. J. Fluid Mech., 5, 113, https://doi.org/10.1017/S002211205900009X.

Brethouwer, G., and E. Lindborg, 2008: Passive scalars in stratified turbulence. Geophys. Res. Lett., 35, L06809, https://doi.org/ 10.1029/2007GL032906.

Callies, J., and R. Ferrari, 2013: Interpreting energy and tracer spectra of upper-ocean turbulence in the submesoscale range (1-200 km). J. Phys. Oceanogr., 43, 2456-2474, https://doi.org/ 10.1175/JPO-D-13-063.1.

— , G. Flierl, R. Ferrari, and B. Fox-Kemper, 2016: The role of mixed-layer instabilities in submesoscale turbulence. J. Fluid Mech., 788, 5-41, https://doi.org/10.1017/jfm.2015.700.

Capet, X., J. C. McWilliams, M. J. Molemaker, and A. Shchepetkin, 2008: Mesoscale to submesoscale transition in the California current system. Part III: Energy balance and flux. J. Phys. Oceanogr., 38, 2256-2269, https://doi.org/10.1175/2008JPO3810.1.

Cole, S. T., and D. L. Rudnick, 2012: The spatial distribution and annual cycle of upper ocean thermohaline structure. J. Geophys. Res., 117, C02027, https://doi.org/10.1029/ 2011JC007033.

D'Asaro, E. A., and Coauthors, 2018: Ocean convergence and the dispersion of flotsam. Proc. Natl. Acad. Sci. USA, 115, 1162-1167, https://doi.org/10.1073/PNAS.1718453115.

Erickson, Z. K., A. F. Thompson, J. Callies, X. Yu, A. N. Garabato, and P. Klein, 2020: The vertical structure of open-ocean submesoscale variability during a full seasonal cycle. J. Phys. Oceanogr., 50, 145-160, https://doi.org/10.1175/JPO-D-19-0030.1.
Essink, S., V. Hormann, L. R. Centurioni, and A. Mahadevan, 2019: Can we detect submesoscale motions in drifter pair dispersion? J. Phys. Oceanogr., 49, 2237-2254, https://doi.org/ 10.1175/JPO-D-18-0181.1.

Ferrari, R., and K. L. Polzin, 2005: Finescale structure of the $T-S$ relation in the eastern North Atlantic. J. Phys. Oceanogr., 35, 1437-1454, https://doi.org/10.1175/JPO2763.1.

Gordon, A. L., E. L. Shroyer, A. Mahadevan, D. Sengupta, and M. Freilich, 2016: Bay of Bengal: 2013 northeast monsoon upper-ocean circulation. Oceanography, 29, 82-91, https:// doi.org/10.5670/oceanog.2016.41.

—, E. Shroyer, and V. Murty, 2017: An intrathermocline eddy and a tropical cyclone in the Bay of Bengal. Sci. Rep., 7, 46218, https://doi.org/10.1038/srep46218.

Hua, B. L., C. Ménesguen, S. Le Gentil, R. Schopp, B. Marsset, and H. Aiki, 2013: Layering and turbulence surrounding an anticyclonic oceanic vortex: In situ observations and quasi-geostrophic numerical simulations. J. Fluid Mech., 731, 418-442, https:// doi.org/10.1017/jfm.2013.369.

Itoh, S., and D. L. Rudnick, 2017: Fine-scale variability of isopycnal salinity in the California Current System. J. Geophys. Res. Oceans, 122, 7066-7081, https://doi.org/10.1002/2017JC013080.

Jaeger, G. S., 2019: Stratified and stirred: Monsoon freshwater in the Bay of Bengal. Ph.D. thesis, Massachusetts Institute of Technology, 121 pp., https://dspace.mit.edu/handle/1721.1/ 122332 .

— sation of fronts in a salinity-stratified ocean. Sci. Adv., 4, e1701504, https://doi.org/10.1126/SCIADV.1701504.

_ A. J. Lucas, and A. Mahadevan, 2019: Formation of interleaving layers in the Bay of Bengal. Deep-Sea Res. II, 172, 104717, https://doi.org/10.1016/J.DSR2.2019.104717.

Jinadasa, S., I. Lozovatsky, J. Planella-Morató, J. D. Nash, J. A. MacKinnon, A. J. Lucas, H. W. Wijesekera, and H. J. Fernando, 2016: Ocean turbulence and mixing around Sri Lanka and in adjacent waters of the northern Bay of Bengal. Oceanography, 29, 170-179, https://doi.org/10.5670/oceanog.2016.49.

Klein, P., A.-M. Treguier, and B. L. Hua, 1998: Three-dimensional stirring of thermohaline fronts. J. Mar. Res., 56, 589-612, https://doi.org/10.1357/002224098765213595.

Klymak, J. M., W. Crawford, M. H. Alford, J. A. MacKinnon, and R. Pinkel, 2015: Along-isopycnal variability of spice in the North Pacific. J. Geophys. Res. Oceans, 120, 2287-2307, https://doi.org/10.1002/2013JC009421.

Kunze, E., and M. A. Sundermeyer, 2015: The role of intermittency in internal-wave shear dispersion. J. Phys. Oceanogr., 45, 2979-2990, https://doi.org/10.1175/JPO-D-14-0134.1.

— J. Klymak, R.-C. Lien, R. Ferrari, C. Lee, M. Sundermeyer, and L. Goodman, 2015: Submesoscale water-mass spectra in the Sargasso Sea. J. Phys. Oceanogr., 45, 1325-1338, https:// doi.org/10.1175/JPO-D-14-0108.1.

Lapeyre, G., and P. Klein, 2006: Dynamics of the upper oceanic layers in terms of surface quasigeostrophy theory. J. Phys. Oceanogr., 36, 165-176, https://doi.org/10.1175/JPO2840.1.

Lévy, M., R. Ferrari, P. J. Franks, A. P. Martin, and P. Rivière, 2012: Bringing physics to life at the submesoscale. Geophys. Res. Lett., 39, L14602, https://doi.org/10.1029/2012GL052756.

Lucas, A. J., and Coauthors, 2016: Adrift upon a salinity-stratified sea: A view of upper-ocean processes in the Bay of Bengal during the southwest monsoon. Oceanography, 29, 134-145, https://doi.org/10.5670/oceanog.2016.46.

MacKinnon, J., L. St Laurent, and A. C. N. Garabato, 2013: Diapycnal mixing processes in the ocean interior. Ocean Circulation and 
Climate, 2nd ed. G. Siedler et al., Eds., International Geophysics Series, Vol. 103, Academic Press, 159-183.

McCaffrey, K., B. Fox-Kemper, and G. Forget, 2015: Estimates of ocean macroturbulence: Structure function and spectral slope from Argo profiling floats. J. Phys. Oceanogr., 45, 1773-1793, https://doi.org/10.1175/JPO-D-14-0023.1.

McWilliams, J. C., 2016: Submesoscale currents in the ocean. Proc. Roy. Soc. London, 472A, 20160117, https://doi.org/10.1098/ RSPA.2016.0117.

Meissner, T., F. Wentz, and A. Manaster, 2018: Remote Sensing Systems SMAP ocean surface salinities [Level 3 Running 8-day]. Version 3.0 validated release, Remote Sensing Systems, Santa Rosa, CA, accessed 15 March 2019, https://doi.org/ 10.5067/SMP30-3SPCS.

Munk, W., 1981: Internal waves and small-scale processes. Evolution of Physical Oceanography, B. A. Warren and C. Wunsch, Eds., MIT Press, 264-291.

Pinkel, R., M. Buijsman, and J. M. Klymak, 2012: Breaking topographic lee waves in a tidal channel in Luzon Strait. Oceanography, 25, 160-165, https://doi.org/10.5670/oceanog.2012.51.

Polzin, K., and R. Ferrari, 2004: Isopycnal dispersion in NATRE. J. Phys. Oceanogr., 34, 247-257, https://doi.org/ 10.1175/1520-0485(2004)034<0247:IDIN>2.0.CO;2.

Prasanna Kumar, S., P. Muraleedharan, T. Prasad, M. Gauns, N. Ramaiah, S. De Souza, S. Sardesai, and M. Madhupratap, 2002: Why is the Bay of Bengal less productive during summer monsoon compared to the Arabian Sea? Geophys. Res. Lett., 29, 2235, https://doi.org/10.1029/2002GL016013.

_ - and Coauthors, 2004: Are eddies nature's trigger to enhance biological productivity in the Bay of Bengal? Geophys. Res. Lett., 31, L15304, https://doi.org/10.1029/2004GL020247.

Ramachandran, S., and Coauthors, 2018: Submesoscale processes at shallow salinity fronts in the Bay of Bengal: Observations during the winter monsoon. J. Phys. Oceanogr., 48, 479-509, https://doi.org/10.1175/JPO-D-16-0283.1.

Ruddick, B., and O. Kerr, 2003: Oceanic thermohaline intrusions: Theory. Prog. Oceanogr., 56, 483-497, https://doi.org/10.1016/ S0079-6611(03)00029-6.

Rudnick, D. L., and J. P. Martin, 2002: On the horizontal density ratio in the upper ocean. Dyn. Atmos. Oceans, 36, 3-21, https:// doi.org/10.1016/S0377-0265(02)00022-2.

_ gliders. J. Geophys. Res., 116, C08010, https://doi.org/10.1029/ 2010JC006849.

Sarma, V., and T. Udaya Bhaskar, 2018: Ventilation of oxygen to oxygen minimum zone due to anticyclonic eddies in the Bay of Bengal. J. Geophys. Res. Biogeosci., 123, 2145-2153, https:// doi.org/10.1029/2018JG004447.

Schmidtko, S., G. C. Johnson, and J. M. Lyman, 2013: MIMOC: A global monthly isopycnal upper-ocean climatology with mixed layers. J. Geophys. Res. Oceans, 118, 1658-1672, https:// doi.org/10.1002/jgrc.20122.

Sengupta, D., G. Bharath Raj, and S. Shenoi, 2006: Surface freshwater from Bay of Bengal runoff and Indonesian throughflow in the tropical Indian Ocean. Geophys. Res. Lett., 33, L22609, https://doi.org/10.1029/2006GL027573.

Shcherbina, A. Y., and Coauthors, 2015: The LatMix summer campaign: Submesoscale stirring in the upper ocean. Bull. Amer. Meteor. Soc., 96, 1257-1279, https://doi.org/10.1175/ BAMS-D-14-00015.1.

Shetye, S., S. Shenoi, A. Gouveia, G. Michael, D. Sundar, and G. Nampoothiri, 1991: Wind-driven coastal upwelling along the western boundary of the Bay of Bengal during the southwest monsoon. Cont. Shelf Res., 11, 1397-1408, https:// doi.org/10.1016/0278-4343(91)90042-5.

Shroyer, E. L., and Coauthors, 2019: Upper layer thermohaline structure of the Bay of Bengal during the 2013 northeast monsoon. Deep-Sea Res. II, 172, 104630, https://doi.org/ 10.1016/j.dsr2.2019.07.018.

, D. L. Rudnick, J. T. Farrar, B. Lim, S. K. Venayagamoorthy, L. C. St. Laurent, A. Garanaik, and J. N. Moum, 2016: Modification of upper-ocean temperature structure by subsurface mixing in the presence of strong salinity stratification. Oceanography, 29, 62-71, https://doi.org/10.5670/ oceanog.2016.39.

Siegelman, L., P. Klein, P. Rivière, A. F. Thompson, H. S. Torres, M. Flexas, and D. Menemenlis, 2020: Enhanced upward heat transport at deep submesoscale ocean fronts. Nat. Geosci., 13, 50-55, https://doi.org/10.1038/s41561-019-0489-1.

Smith, K. S., and R. Ferrari, 2009: The production and dissipation of compensated thermohaline variance by mesoscale stirring. J. Phys. Oceanogr., 39, 2477-2501, https://doi.org/10.1175/ 2009JPO4103.1.

Sundermeyer, M. A., and J. R. Ledwell, 2001: Lateral dispersion over the continental shelf: Analysis of dye release experiments. J. Geophys. Res. Oceans, 106, 9603-9621, https:// doi.org/10.1029/2000JC900138.

$\longrightarrow,-$, N. S. Oakey, and B. J. Greenan, 2005: Stirring by smallscale vortices caused by patchy mixing. J. Phys. Oceanogr., 35, 1245-1262, https://doi.org/10.1175/JPO2713.1.

Thomas, L. N., and C. J. Shakespeare, 2015: A new mechanism for mode water formation involving cabbeling and frontogenetic strain at thermohaline fronts. J. Phys. Oceanogr., 45, 2444-2456, https://doi.org/10.1175/JPO-D-15-0007.1.

, A. Tandon, and A. Mahadevan, 2008: Submesoscale processes and dynamics. Ocean Modeling in an Eddying Regime, Geophys. Monogr., Vol. 177, Amer. Geophys. Union, 17-38.

Thompson, A. F., A. Lazar, C. Buckingham, A. C. Naveira Garabato, G. M. Damerell, and K. J. Heywood, 2016: Open-ocean submesoscale motions: A full seasonal cycle of mixed layer instabilities from gliders. J. Phys. Oceanogr., 46, 1285-1307, https:// doi.org/10.1175/JPO-D-15-0170.1.

Thomson, R. E., and W. J. Emery, 2014: Data Analysis Methods in Physical Oceanography. Newnes, 728 pp.

Vallis, G. K., 2017: Atmospheric and Oceanic Fluid Dynamics. Cambridge University Press, 745 pp.

Woods, J. D., R. Onken, and J. Fischer, 1986: Thermohaline intrusions created isopycnically at oceanic fronts are inclined to isopycnals. Nature, 322, 446-449, https://doi.org/10.1038/322446a0.

Yi-Neng, L., P. Shi-Qiu, and Z. Xue-Zhi, 2012: Observations and simulations of the circulation and mixing around the AndamanNicobar submarine ridge. Atmos. Ocean. Sci. Lett., 5, 319-323, https://doi.org/10.1080/16742834.2012.11447008.

Young, W., P. Rhines, and C. Garrett, 1982: Shear-flow dispersion, internal waves and horizontal mixing in the ocean. J. Phys. Oceanogr., 12, 515-527, https://doi.org/10.1175/ 1520-0485(1982)012<0515:SFDIWA $>2.0$. CO;2.

Yu, X., A. C. Naveira Garabato, A. P. Martin, C. E. Buckingham, L. Brannigan, and Z. Su, 2019: An annual cycle of submesoscale vertical flow and restratification in the upper ocean. J. Phys. Oceanogr., 49, 1439-1461, https://doi.org/10.1175/ JPO-D-18-0253.1. 